Review

\title{
Tuning the Cell and Biological Tissue Environment through Magneto-Active Materials
}

\author{
Jorge Gonzalez-Rico ${ }^{1}$, Emanuel Nunez-Sardinha $\left.{ }^{1,2}{ }^{(}\right)$, Leticia Valencia ${ }^{3}{ }^{(D}$, Angel Arias ${ }^{1}{ }^{(0)}$, \\ Arrate Muñoz-Barrutia ${ }^{3,4}\left(\mathbb{D}\right.$, Diego Velasco ${ }^{3,4}$ (D) and Daniel Garcia-Gonzalez ${ }^{1, *(D)}$ \\ 1 Department of Continuum Mechanics and Structural Analysis, Universidad Carlos III de Madrid, Avda. de la \\ Universidad 30, Leganes, 28911 Madrid, Spain; jorgegon@ing.uc3m.es (J.G.-R.); \\ Emanuel.NunezSardinha@uwe.ac.uk (E.N.-S.); aariash@ing.uc3m.es (A.A.) \\ 2 Bristol Robotic Lab, University of West England, Bristol BS16 1QY, UK \\ 3 Department of Bioengineering and Aerospace Engineering, Universidad Carlos III de Madrid, Avda. de la \\ Universidad 30, Leganes, 28911 Madrid, Spain; lvalenci@ing.uc3m.es (L.V.); \\ mamunozb@ing.uc3m.es (A.M.-B.); divelasc@ing.uc3m.es (D.V.) \\ 4 Instituto de Investigación Sanitaria Gregorio Marañón, Calle de O'Donnell, 48, 28009 Madrid, Spain \\ * Correspondence: danigarc@ing.uc3m.es
}

check for updates

Citation: Gonzalez-Rico, J.; Nunez-Sardinha, E.; Valencia, L.; Arias, A.; Muñoz-Barrutia, A.; Velasco, D.; Garcia-Gonzalez, D. Tuning the Cell and Biological Tissue Environment through

Magneto-Active Materials. Appl. Sci. 2021, 11, 8746. https://doi.org/ 10.3390/app11188746

Academic Editor: Antonio Scarano

Received: 4 August 2021

Accepted: 2 September 2021

Published: 19 September 2021

Publisher's Note: MDPI stays neutral with regard to jurisdictional claims in published maps and institutional affiliations.

Copyright: (c) 2021 by the authors. Licensee MDPI, Basel, Switzerland. This article is an open access article distributed under the terms and conditions of the Creative Commons Attribution (CC BY) license (https:// creativecommons.org/licenses/by/ $4.0 /)$.

\begin{abstract}
This review focuses on novel applications based on multifunctional materials to actuate biological processes. The first section of the work revisits the current knowledge on mechanically dependent biological processes across several scales from subcellular and cellular level to the cellcollective scale (continuum approaches). This analysis presents a wide variety of mechanically dependent biological processes on nervous system behaviour; bone development and healing; collective cell migration. In the second section, this review presents recent advances in smart materials suitable for use as cell substrates or scaffolds, with a special focus on magneto-active polymers (MAPs). Throughout the manuscript, both experimental and computational methodologies applied to the different treated topics are reviewed. Finally, the use of smart polymeric materials in bioengineering applications is discussed.
\end{abstract}

Keywords: biomechanics; mechanobiology; magneto-active polymers; magnetorheological elastomers; ferrogels; constitutive modelling; cell migration; tissue remodelling; 3D printing

\section{Introduction}

Recent decades have experienced a revolution in our understanding of several biological processes, such as cell migration, development, healing or physiological responses. These processes, further from being independent behaviours, have been demonstrated to highly influence each other, leading to complex multi-physical interplays of different natures. Among these interrelations, mechanical cues have a very significant impact on almost all of them. Interestingly, the mechanics occurring within the cells are determined not only by their microstructural arrangement but also by the external mechanical conditions through universal momentum balance laws. Being aware of this, scientists around the world have focused their efforts on developing controllable scaffolds and substrates to take advantage of these mechanical links to influence cells behaviour. In this regard, recent works provide novel techniques to smartly design the manufacture of polymeric cell scaffolds and substrates by customizing mechanical properties, such as stiffness, ductility or viscoelasticity. In addition, pioneering efforts are being developed to manufacture polymeric substrates with controllable dynamic properties. Among the latter, magnetoactive polymers (MAPs), in their different types, have outstanding dynamic mechanical properties through the remote application of an external magnetic field.

This review revisits, in Section 2, a wide variety of mechanically dependent biological processes and focuses, ultimately, on collective cell migration. The computational modelling strategies to simulate these processes are then introduced in Section 3. A second 
block of the review relates to multifunctional materials that mechanically respond to magnetic stimuli. In this regard, Section 4 presents recent advances in smart materials that are suitable for use as cell substrates or scaffolds, with a special focus on MAPs. This is complemented, in Section 5, with a comprehensive analysis of the state of the art on the modelling of such materials. Finally, we merge both blocks of the review to discuss current and future bioengineering solutions based on MAPs.

\section{Mechanically Mediated Biological Processes}

Most biological processes are governed by a complex interplay between a wide variety of physicochemical cues. Among these, mechanical variables such as stress and deformation play a key role in the final behaviour. Some examples of mechanical effects on biological responses are alterations in the electrophysiological behaviour of the nervous system, healing process in the bone marrow, and promotion of cell migration patterns, to name a few (see Figure 1). Therefore, the study of such mechanical influences on the behaviour of biological cells and tissues has become one of the most active research areas. In this section, we present some examples of how these mechanical effects may impact different biological processes.

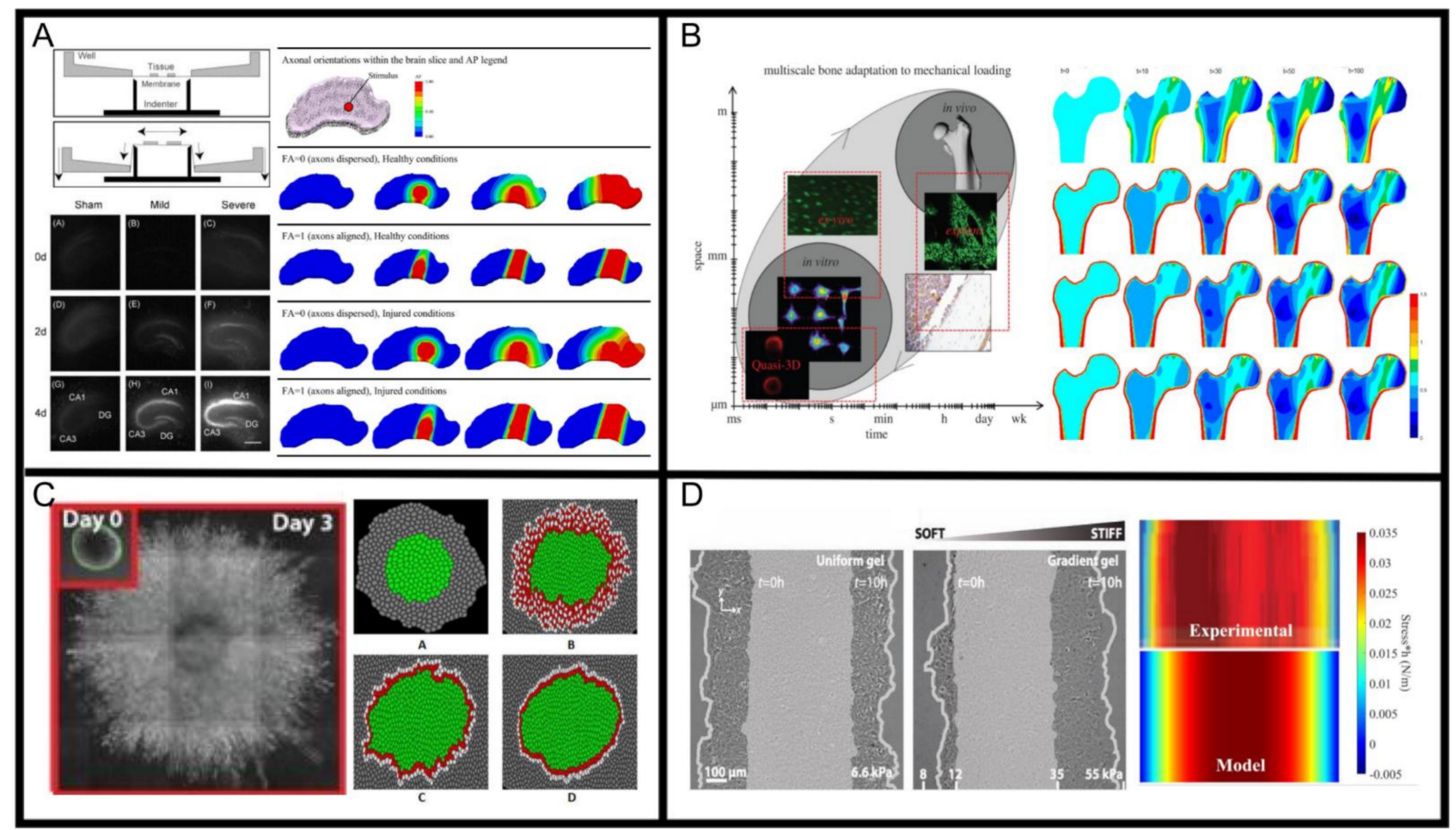

Figure 1. Examples of biological cells and tissue, whose functional response greatly depends on mechanical effects: (A) mechano-electrophysiological response in brain tissue, experimental (adapted with permission from [1]) (left) and modelling (adapted with permission from [2]) (right) insights; (B) bone adaptation to mechanical loading, experimental (adapted with permission from [3]) (left) and modelling (adapted with permission from [4]) (right) insights; (C) cancer cell proliferation and migration depending on mechanical properties of the substrate, experimental (adapted with permission from [5]) (left) and modelling (adapted with permission from [6]) (right) insights; (D) durotaxis in epithelial cell migration depending on mechanical properties of the substrate, experimental (adapted with permission from [7]) (left) and modelling (adapted with permission from [8]) (right) insights.

\subsection{Mechanical Effects on Nervous System Behaviour}

Unlike other types of tissue, brain cell mechanical properties are not as clearly understood and are much more difficult to study and generalize $[9,10]$. The number of physical and chemical variables, external and internal factors, as well as structure, creates complicated loops that make it hard to distinguish cause from effect. However, outstanding 
progress has been made in deciphering and using the mechano-properties as indicators of problems.

The central nervous system is mainly comprised of neurons supported by glial cells and display the behaviour of elastic solids [11]. However, this interpretation is often debated, as glial cells present significantly softer characteristics than the cells they support. Some glial cells are twice as soft as neurons and present lower elastic storage modulus and viscous loss modulus. Experiments have determined that these cells' functions resemble more of a cushioning system or flexible embedding than a scaffold, protecting neurons from mechanical trauma, displaying very elastic properties [12]. The cells themselves are tightly held in place by cerebrospinal fluid. This in turn also applies pressure over the nervous system, which can increase considerably in the case of trauma. Although elastic behaviour dominates over viscous behaviour across the nervous systems, properties differ due to the varying distribution of organelles.

Many efforts have been made in identifying causes for medical complications in patients of traumatic incidents. Understanding the specific triggers and mechanisms behind traumatic brain damage and its development into neurodegenerative and neuropsychiatric disorders is an ongoing challenge. In the case of external trauma, pathologies are thought to be mechanically initiated and to result in many interconnected variables and processes. Some properties, such as shear deformation energy, which naturally varies during the lifecycle of the cell/tissue may be used as an indicator of trauma. The associated damage at the axonal or tissue scale, especially relevant at high deformation rates, can result into electrophysiological alterations and, following this, loss of sensory and motor function $[2,13]$. Damageable mechanical conditions are likely to occur during loading scenarios, such as sport activities, falls, and car accidents [14], or during even more dangerous scenarios such as blast loading (e.g., explosions) [15]. Therefore, the identification of clear links between mechanics and functional and cognitive deficits is of great interest. To this end, different criteria have been proposed to identify and predict such physiological alterations due to mechanical effects (i.e., axonal stretch, deformation energy, deformation energy rate) $[1,2,16,17]$.

In the same way that chemical changes affect the properties of the system, mechanical processes affect the final chemical properties, causing a feedback loop. This two-way effect is most evident in signalling, as the capacity for generating action potentials can be affected by trauma. Several experiments, replicating traumatic injuries in rats, lead alterations in the intracellular medium, most notably a sharp increase in the number of $\mathrm{Ca}^{2+}$ ions. In turn, altered chemical conditions of these neurotransmitters can affect the composition of the extracellular media. Different pathologies can also influence the mechanical conditions of the nervous system. In the case of stroke, a reduction in blood flow and oxygen in the brain, post-accident conditions can cause long-term effects on the brain [18-20]. The breakdown of the tight blood-brain barrier junction causes dramatic swelling, and the subsequent brain expansion leads to an increase in intracranial pressure and temperature. Oedema (fluid collection) is a dangerous possibility, resulting in permanent damage.

\subsection{Mechanical Effects on Bone Development and Healing}

Many mechanical factors play a significant role in bone development and in the healing process. Bones as an organ system are particularly sensitive to mechanical stimuli: a fully developed skeleton continues changing through the course of its life, influenced, shaped, strengthened and weakened by the multiple mechanical forces acting upon it. The different stages of bone creation, development and healing are affected and regulated by the collective mechanical environment [3,4,21,22].

Mechanics on osteogenesis: Fundamentally, external stimulation is a key variable in the creation of bone. Dating back to 1892, Wolff's law on bone remodelling proposes how bone density is affected by external loads, nutritional factors, and metabolism [23]. Wolff's experiments involved applying external forces directly, leading to an observable change in bone density, indicating growth. Conversely, the absence of forces has the opposite effect, 
weakening the bones and increasing the risk of atrophy [24]. Osteogenesis, the creation of bone cells, requires a stable mechanical environment to succeed. Pauwels' hypothesis postulates that mechanical deformation results in the production of connective tissue, hydrostatic compression causes cartilage formation, and their combination leads to the appearance of fibrocartilage [25]. These mechanical dependences have been modelled, as in the work by Claes and Heigele [26], which presented a model correlating hydrostatic pressure and strain rates to different types of ossification. Overall, the environmental mechanical properties promote the formation of the tissue that better adapt to the surrounding by means of stress and deformation compatibility. Softer tissue is promoted within soft mechanical environments while stiffer tissue formation is favoured within the stiffer regions. In this approach, intramembranous ossification occurs for low strains and compressive pressures (less than $5 \%$ and less than $0.15 \mathrm{MPa}$, respectively), whereas endochondral bone formation occurs at larger strain levels. Similarly, cartilage formation is promoted within high compression zones (performing a shock absorption role) and fibrocartilage within high strain regions (tolerating high deformation) [26,27].

Mechanics on bone fracture: In bone fractures, the body is capable of sequentially producing the specific physical conditions needed for the reconstruction process. Following an accident, the body forms a hematoma in situ, where signalling molecules are released (cytokines and growth factors). The hematoma increases the volume and pressure at the wound through inflammation. This hematoma acts as the first "filling" agent, providing structural support for cells and kickstarting their differentiation into fibrous tissue, cartilage, and bone. If the hematoma phase is interrupted, the sufficient stability conditions for regeneration are not fulfilled, causing delayed or failed healing [28]. Following the inflammatory phase and once initial stabilisation is reached, a tight union (bones fixed together) at sufficient high pressure leads to primary bone healing. In primary healing, a callus does not form, and tissue is healed directly by osteoclast and osteoblast activities. Given that bone is essentially restored to its previous state, the volume remains constant [29]. In the case of joints, primary healing is desired but not always possible, and an open reduction (surgical fixation of the area) may be necessary to guarantee a stiff union [30]. Bone forms when external stimulation is kept to a minimum, but the ideal mechanical environment for bone healing and its normal active state differ. While minimum disturbance supports healing, it can also cause healthy bone atrophy and be reabsorbed. Other factors than fixation stability, such as age of the wound and subject and nature of the wound also play a role [31].

If instead of a rigid environment, the bones are allowed a small degree of motion, secondary healing occurs, where a soft callus forms in the gap area. Bone formation with interfragmentary motion needs the presence of the bridging callus, tissue that forms to connect two broken pieces of bone, only appearing under specific strain rates. This soft callus formation (proliferative) phase develops through two processes: (i) endochondral ossification, where Mesenchymal Stem Cells (MSCs) differentiate into chondrocytes, creating cartilage tissue; and (ii) intramembranous ossification, where MSCs differentiate into osteoblasts and bone is directly created. In the latter, the resulting cartilage extracellular matrix mineralizes, and osteoblasts can lay down bone tissue. Next, in the hard callus formation (maturing or modelling) phase, the generated cartilage is used as a support scaffold, and mineralized into bone matter by the osteoblasts [32,33]. The final stage is the remodelling phase, in which secondary bone formation occurs, reshaping and reabsorbing bone, as needed, to restore the initial shape and strength [34]. If the necessary physical conditions are not maintained, however, it may not be possible to ensure ideal conditions in all scenarios. Failing to fixate bones properly after a fracture or providing too strict a support may cause the process to halt or revert. If high strain exists at the fracture site during the initial stages of formation, fibrous tissue cannot be replaced by bridging callus tissue, resulting in a failed fibrous non-union [35]. As mentioned before, the creation of new bone is not ideal in articulations, as the formation of a callus could interfere with normal activity, and thus normally relies on external or surgical fixation. 
Moreover, bone healing does not only depend on the magnitude and nature of the forces applied, but also their frequency of application, with evidence of the possible effect on the formation of connective tissue. Regarding the distraction rate (tension applied to the bone in $\mathrm{mm} /$ day), contradictory studies exist, suggesting both the independence and negative effect on the healing process. Ghiasi proposes an unequal response to compression and tension to explain this inconsistency, with evidence suggesting that compression is necessary or beneficial to some healing processes [36]. Macro forces acting on the tissue, such as strain, pressure, stability, and fluid velocity are known to have a mechanical effect on the individual cell matrix, affecting their function, migration, and differentiation, but the interrelation remains poorly understood. Other works on both experimental and computational modelling of bone healing can be found in the literature [37-39].

\subsection{Mechanical Effects on Collective Cell Migration Underlying Morphogenesis Tissue Regeneration and Cancer Progression}

Collective cell migration is a major player in different biological processes, such as wound healing, embryonic development, or cancer progression. In such migration, cells move as sheets, strands, clusters or ducts, rather than individually. In collective cell migration, cells use similar actin- and myosin-mediated protrusions and guidance by extrinsic chemotactic and mechanical cues, such as that exploited by single migratory cells. However, cadherin-based junctions between cells adds 'supracellular' properties, such as collective polarisation, force generation, decision making and, eventually, complex tissue organisation [40]. An additional force-generating property, the ability to generate cell protrusions, also contributes to active motility. These mechanical properties can be regulated independently in cells, suggesting that they can be employed in a combinatorial manner. This could generate a diverse array of cell shapes and arrangements orchestrating the varied morphogenetic events observed during organ development.

During these processes, cells continuously interact between them and with their surroundings, i.e., extracellular matrix (ECM). These interactions result into a complex system of physicochemical cues that, in turn, travel within the cellular aggregate and lead to a cellular continuum that moves together. Among the physicochemical signals, mechanical waves constitute one of the most relevant vehicles in transmitting the information between cells and guiding the collective migration process. In this regard, mechanical waves help with coordinating the cellular behaviour by sharing, within the whole continuum, cellular crosstalk, cell-cell and cell-ECM adhesive interactions, and active responses from cell contractility [41]. Interestingly, during morphogenesis, mesoderm tissue stiffening initiates an epithelial-to-mesenchymal transition in neural crest cells and triggers their collective migration. More broadly, tissue mechanics combine with molecular effectors to coordinate morphogenesis [42].

When looking at cells from a mechano-structural point of view, they are usually modelled as a combination of viscous and elastic substances, similar to non-Newtonian fluids, meaning that stresses tend to relax with time. This viscoelastic behaviour allows the cell to adapt to the stress over time. Moreover, the ECM contains proteins such as collagen, elastin, laminin and perlecan. These greatly vary from relatively soft, such as in brain tissue with a shear modulus in the order of $1 \mathrm{kPa}$, to cartilage with a respective value closer to $1 \mathrm{MPa}$. These elements tend to be orders of magnitude tougher and impassable for cells, but are neither perfectly packed nor distributed, having inner gaps that are large enough for the cells to pass through. Other forces keeping them attached to the extracellular matrix, mainly those exerted by actin and myosin, are subject to substantial contractile forces, generating elevated internal stress. This dampens movement but does not outright impede it. Surprisingly, the migration mechanism can be reduced to purely mechanical phenomena. In simple terms, cells move when there are unbalanced forces driving the movement in a particular direction. For example, the closure of epithelial gaps in the absence of cell injury is governed by the collective migration of cells through the activation of lamellipodium protrusion [43]. Traction forces are constantly being altered, and the cells move in the proper direction to minimise the newly achieved stress, in a process mimicking diffusion. 
Therefore, the controlled tuning of the ECM seems a powerful idea to, at some instance, influence the cell migration process and it has been explored as an emerging therapy [44].

Numerous studies have been conducted to date to elucidate the specific effects of ECM's mechanical properties on cell migration. Anisotropic ECM promotes the heterogeneous distribution of mechanical forces acting within the cell continuum [8]. The resulting interplay between external forces and cellular stresses modulates changes in the cellular shape and provides preferred directions for collective migration. More concretely, cells tend to migrate along gradients of substrate stiffness [45]. This behaviour is termed as durotaxis and is postulated as one of the main promoters of cell movement to stiffer regions [46]. Experiments conducted by Sunyer et al. [7] corroborate these premises and demonstrate that stiffness gradients within the substrate induce collective cell migration towards the stiffer regions.

Collective invasion is prevalent in cancer $[5,6]$. However, because cancer is a slow, long-term process that is not amenable to direct microscopy observation, to date the mechanisms of collective cell migration are less understood compared with morphogenesis and regeneration [40]. In histopathological sections, most epithelial cancers display the hallmarks of collective invasion into surrounding tissues, including intact cell-cell junctions, the expression of cadherins and other cell-cell adhesion receptors. Moreover, structural ECM degradation and remodelling due to the engagement of cell surface proteases is an early event in collective cancer cell movement. Besides, cancer cells exhibit gap junctional communication, which suggest cell-cell coupling and multicellular organisation. Local tissue remodelling caused by collective invasion, might contribute to invasive tumour growth and consecutive tissue destruction. In experimental models of metastasis, cancer cells survive in the blood steam and generate lung metastases [47]. In certain cancers, such as melanoma, cancer cells travel inside lymphatic vessels and increase the risk for lymphatic metastasis [48].

Because intact and coordinated cell-cell junctions are critical for mass invasion, the gain or loss of cell-cell coupling determines whether cancer cells move collectively, individually, or use transition patterns. Consequently, three-dimensional migration in tumour cells can develop through the mesenchymal phenotype (elongated cell shape) or amoeboid type (rounded cell shape). This determines the migration mechanisms which, in the mesenchymal cell, present high adhesion, high polarisation and protrusions rich in actin; while in the amoeboid they present low adhesion, low polarisation and the formation of blisters or 'blebs' in the cell membrane [49] In this context, the role that the mechanical processes play is even more relevant, since it can lead to transitions between both migration mechanisms. For example, the application of vertical compression in cells where adhesion with the substrate is low, induces a transition from mesenchymal to amoeboid migration [50]. Therefore, it can be concluded that the physical properties of the substrate or ECM, highlighting the mechanical properties among them, together with the intrinsic properties of the cells themselves, regulate the mechanisms and modes of migration [51]. This influence of the mechanical properties of the cell environment is also of great relevance for proliferation processes. The understanding of these aspects would be of great importance to advance in the control of cancerous processes, such as tumour progression and metastasis.

\section{Theoretical and Computational Frameworks for Mechanically Mediated Biological Processes}

The conceptualisation and complete understanding of mechanical effects on biological processes is always complex as it requires the combination of multidisciplinary approaches, involving not only mechanics but also other physics. Additional difficulties arise from limitations of the current experimental methodologies. To overcome these issues, theoretical and computational approaches are conceived providing further insights in the analysis of the data and allowing for the testing hypothesis. This section introduces some modelling trends on the influence of mechanical effects on the electrophysiology of the nervous system, bone development and healing, and collective cell migration. 


\subsection{Modelling Mechanical Effects on Nervous System Behaviour}

The last few decades have experienced an emergence in interest of the scientific community in modelling both mechanical and electrophysiological behaviours of the nervous system from cell to tissue scales. Among these works, it is worth highlighting studies that address the mechano-electrophysiological problem from two main views: alteration of physiological responses due to mechanical damage; and intrinsic coupling of electrophysiology and mechanics during action potential formation and propagation.

The search for criteria to link mechanical variables and functional deficits presents important limitations from experimental approaches. Computational models offer not only the possibility of analysing the problem by means of stress, strain and other mechanical variables, but also to translate knowledge and hypotheses from animal models to humans [16]. These computational tools have been used to provide the quantitative evaluation of mechanical effects on spinal cord injury [52], on the central nervous system [53-56] and on functional and cognitive deficits [2,57]. One of the first models to describe, in a coupled manner, both mechanics and electrophysiology is due to Boucher et al. [58]. In this work, the authors analysed left shift dynamics of ionic channel resulting from trauma conditions. Other pioneering work is due to Babbs and Shi [59] and focused on mild retraction of myelin due to stretch and crush injuries. These ideas were then taken by Jerusalem and co-authors and incorporated into 1D [60,61] and 3D [62] finite element frameworks to explore the effects of mechanical deformation and strain rate on axonal electrophysiology. In addition, alternative 3D non-axisymmetric mechano-electrophysiological models have been proposed [63-65]. Finally, in a recent series of works, Garcia-Gonzalez and co-authors have proposed novel mechanistic energy-based criteria to link mechanical effects directly to medium-term cognitive deficits [57] and alterations in the electrophysiological behaviour at tissue scale [2,57].

Moreover, interesting experimental observations on the electro-mechanical coupling in neuronal membrane have led to new paradigms in the conceptualisation of the action potential nature. In this regard, different numerical approaches have been proposed. El Hady and Machta [66] related the variation of compressive electrostatic forces (arisen from electrical depolarisation) within the membrane to mechanical waves called action waves. Engelbrecht and co-authors have developed, in a series of articles [67-69] new theories that conceive action potential as an electrical wave that triggers other processes such as pressure waves in the axoplasm or longitudinal and transverse waves in the membrane. Finally, Chen et al. [70] developed a mechano-electrophysiological model for neuronal axons, where the electro-mechanical coupling is explained by flexoelectric effects. More information on this can be found in a recent review article by Jerusalem et al. [71].

\subsection{Modelling Mechanical Effects on Bone Development and Healing}

The interconnected multiscale nature of bone reconstruction and growth makes their modelling very challenging. Regarding these links through the scales, bone, cartilage and other fibrous tissues provide a scaffold/environment that supports cellular scale behaviour, which in turn is responsible for tissue synthetisation [72]. Furthermore, the cellular function is governed by signalling molecules and gene activation at the intracellular level, whose development is highly influenced by the extracellular environment [73]. To overcome the experimental limitations and difficulties to deeply understand such mechanisms, theoretical and computational modelling highlight as tools for testing hypotheses and further study these processes through the different scales. In this regard, Ghiasi [36] neatly classified the historical stages of modelling techniques into mathematical, biological and mechano-biological. Mathematical models are primarily concerned with the influence of mechanical loads on bone development. These models have suggested a localised mechanical behaviour within the healing area and have provided direct relations with the resulting tissue [26]. Despite their evolution, mathematical models are thought to lead primarily to a qualitative understanding of the behaviour of the tissue. These models experienced a significant advance when, aiming at predicting cell behaviour, different biological characteristics 
and behaviours were incorporated. To this end, they were extended to account for time varying processes representing the flux of conditions in the healing stage, independent cellular activity, growth factor production and angiogenesis [39]. These improved formulations have allowed for exploring the role of the cell, extracellular matrix and growth factors concentrations on haptotactic and haptokinetic migration speed, cell proliferation rate, and cell differentiation [74,75]. Buenzli et al. [76] examined osteoblast activity and its effect on reconstruction until apoptosis, while Carlier et al [77], [78] added cellular and intracellular activity, further raising the possibility of incorporating cell movement and directional angiogenesis.

Moreover, mechanobiological models seek to amend the lack of mechanical phenomena in the previous analyses. These approaches have helped with exploring the effect of tissue patterning, defined by the arrangement, location, migration and subsequent changes of cells and extracellular matrix. The accuracy of mechanobiological methods is hampered by the increase in complexity of the systems, often dealing with interconnected $\mathrm{PDE}$, finite element (FE) problems, lattice-based models and the modelling of biological processes [79-81]. For the incorporation of mechanical stimuli, different variables have been proposed showing a good correlation with experimental data: intermittent hydrostatic stress, octahedral shear strain, deviatoric and dilatational strain [82], substituting fluid velocity for hydrostatic pressure $[79,83]$ or a combination of these $[84,85]$. Other approaches based on experimental studies include differences in linearity during healing based on phenotype [86]. More complex approaches include sequentially two or more of the phases in bone healing: inflammation phase, soft callus, hard callus and remodelling, delays between cell stimulation and tissue formation, effect of callus reabsorption in geometry [36]. More recently, based on the pioneering work by Oller and Bellomo [87], other approaches explore the mechanics of bone growth and regeneration under fixed forces and additional biological constraints, accounting for bone growth dynamics, depending on the availability of nutrients and hormones. To this end, the authors developed a finite element (FE) formulation for finite deformations coupling nonlinear mechanics with a mass proliferation equation, whose dynamics are governed by mechanical stimuli and internal variables associated with the nutrients and hormones. These results showed the role of nutrient concentration, suggesting that low availability severely dampens the speed of bone density evolution, resulting in lower inner density, but eventually converging into the expected final state. Moreover, the depletion of nutrients can result in accelerated atrophy, and a much slower increase in density in key support areas.

3.3. Modelling Mechanical Effects on Collective Cell Migration Underlying Morphogenesis Tissue Regeneration and Cancer Progression

The modelling of collective cell migration processes has been addressed mainly during the last decade. In this sense, different approaches covering different physical descriptions and scales have been used to model collective cell migration [88]. The lattice and phase field models describe the shape of the system at the subcellular level; however, the former are not suitable for incorporating some relevant cellular interactions to describe collective cell migration. Particle models are based on the physics of particulate media as granular materials. Although with less details of the cell shape, these can capture anisotropies in the geometry and allow the study of how and what interactions determine the mechanical state of tension of a tissue. Finally, continuous models describe cells as a whole at the coarse-grained level on the multicellular scale. Continuum models are most effective at this scale, as they describe the physical forces, flow, and deformation patterns that mediate collective cell migration during certain processes: wound healing, tissue development, and metastasis, among others. These models are based on the coupling of different governing equations: mass balance (cell proliferation dynamics); mechanical balance between cells and ECM; cell polarisation dynamics; dynamics of actomyosin concentration; and chemical diffusion processes. Mechanical equilibrium is affected by other physicochemical processes and determines the evolution of cell migration and proliferation, imposing a balance between internal cell stresses and external mechanical sources. Köpf and Pismen [89] 
proposed a continuous model, modified by Alert et al. [90], for collective cell migration during unrestricted epithelial spread, which is a key mechanism in embryogenesis and wound healing, to reproduce the spontaneous formation of finger-like protrusions. This model describes the tissue as a polarizable elastic layer that interacts chemically and mechanically. Within the tissue, various chemical species diffuse, generating an active force along the direction of polarisation. Furthermore, Alert et al. [90] proposed a continuous active polar fluid model for epithelial propagation where they demonstrated that epithelial fingering can arise naturally from generic morphological instability in a fluid film driven by interfacial active forces. Notbohm et al. [91] developed a continuous model to examine the internal variables that generate cell polarisation and oscillatory waves. In another work, Garcia-Gonzalez and Muñoz-Barrutia [8] formulated a model that shows how the mechanics of the continuum can serve to test hypotheses about collective cell migration, more specifically, about the mechanical consequences of cell polarisation and the force of propulsion during durotaxis. Regarding current modelling approaches in cancer cell biology, the papers can be consulted in the References section [92,93].

\section{Fundamentals of Smart Polymeric Materials: Focus on Magneto-Active Elastomers and Hydrogels}

In the previous sections, the importance of mechanical effects on different biological processes has been highlighted. In the following section, we present multifunctional materials, i.e., magneto-active polymers (MAPs), as ideal candidates to remotely control the cellular or tissue mechanical environment.

\subsection{Introduction to Smart Polymeric Materials}

Smart polymeric materials are a kind of material that undergo a reversible change in their properties as a consequence of an environmental variation. Depending on the material, these variations in the environment, referred as stimuli, can be changes in temperature, $\mathrm{pH}$, light intensity, presence or absence of electrical and magnetic fields, the presence of certain biological molecules, etc. (Table 1) [94]. The response of smart polymeric materials to these stimuli consist in changes on the nanoscale level, such as the formation of new molecular bonds or the cleavage of previously existing ones, rearrangement of the molecules, morphology changes, etc., or changes at the structural level, such as swelling, collapse or solution-to-gel transitions [95,96]. Additionally, some smart materials present interesting and unique properties, such as shape-memory and self-healing behaviour. Thanks to these properties, these pose as an interesting candidate for biomedical applications. These polymers used for biomedical applications are known as smart biomaterials and are those that can undergo changes in a physiological environment as a response to either internal or external stimuli $[97,98]$. Their use is present in many fields of biomedicine, such as tissue engineering, drug delivery, immune engineering and development of pioneer medical devices, mainly due to two factors: the growing interest in the application of personalised medicine and the emergence of gene and immune therapies, that would greatly benefit from the use of target specific delivery systems; the advances in fabrication techniques, such as $3 \mathrm{D}$ printing, that allow for the fabrication of complex structures that leverage this responsive nature of the materials. 
Table 1. Summary of multifunctional materials according to the nature of their stimulation and highlighting of applications.

\begin{tabular}{|c|c|c|}
\hline Stimulus & Materials & Applications \\
\hline Temperature & $\begin{array}{l}\text { PNIPAAm, PDEAAm, PVCL, PDMAEMA, PEG } \\
\text { [99-106]. }\end{array}$ & $\begin{array}{l}\text { Drug and gene delivery, tissue engineering } \\
\text { (substrates and injectable gels). }\end{array}$ \\
\hline Light & $\begin{array}{l}\text { PEG and PMA hydrogels modified with light } \\
\text { responsive pyrenylmethyl esters, o-nitrobenzyl } \\
\text { esters or coumarinyl esters [107]. }\end{array}$ & $\begin{array}{l}\text { Drug delivery (light can penetrate the skin); } \\
\text { smart surfaces; nanostructures. }\end{array}$ \\
\hline Electrical field & $\begin{array}{l}\text { Ionic polymer-metal composites: perfluorinated } \\
\text { polymers and styrenic copolymers [108]. }\end{array}$ & $\begin{array}{l}\text { Drug delivery, actuators in soft robotics, } \\
\text { artificial muscles [109]. }\end{array}$ \\
\hline Magnetic field & $\begin{array}{l}\text { Polymeric matrix laden with magnetic particles } \\
\text { (nano or micro, hard or soft) [110-115]. }\end{array}$ & $\begin{array}{c}\text { Frug delivery, remote actuation, soft robotics, } \\
\text { tissue engineering. }\end{array}$ \\
\hline $\mathrm{pH}$ & $\begin{array}{l}\text { Polyelectrolyte polymers with weak acidic or basic } \\
\text { groups that accept or release protons in response to a } \\
\text { change in the environmental pH [116]. }\end{array}$ & Drug delivery, gene carriers, biosensors. \\
\hline Biomolecules & $\begin{array}{l}\text { Polymers modified to respond to the presence of } \\
\text { certain biological cues (signals, enzymes, ATP, etc.) } \\
\text { [117]. }\end{array}$ & $\begin{array}{l}\text { Drug delivery, biosensors, tissue engineering } \\
\text { and regenerative medicine. }\end{array}$ \\
\hline
\end{tabular}

\subsection{Magnetorheological Elastomers (MREs)}

Magnetorheological elastomers (MREs) are smart polymeric materials that change mechanical or physical properties when an external magnetic field (EMF) is applied. They are the combination of a polymeric network with nano- and micron-sized magnetic particles. The magnetic interaction of the particles in the presence of a magnetic field is transmitted as forces to the polymeric matrix. These forces acting on the polymeric network result in either deformation or a change in the mechanical properties of the material [118]. The first one is commonly known as magnetostriction, and it consists of the deformation of the polymeric network induced by an external magnetic field. Although magnetostriction is a universal phenomenon for almost all ferromagnetic materials, it is more noticeable in MREs due to their viscous and elastic properties, mainly their softness. The second important feature of MREs, and maybe the more intriguing, is referred to as magneto-rheological (MR) effect. This phenomenon is explained as the change of material stiffness in the presence of a magnetic field. An increase in the shear and tensile moduli under an EMF have both been observed for MREs [119]. Unlike magnetostriction, the magneto-rheological effect is rarely observed in conventional ferromagnetic materials, making magneto-active materials a unique kind of material [120].

Due to the composite nature of these kinds of material, attention must be set on the two components that form them: the matrix material, which is a polymer that gives the MREs their basic mechanical properties and shape; the magnetic particles, which are of micron- or nano-size and give the MREs their responsiveness to external magnetic fields. The most used polymeric materials for the fabrication of MREs are silicone rubbers, due mainly to their availability as resins, in liquid state, which facilitates the homogeneous distribution of the magnetic particles and the easy suspension of the particles during the synthesis process. Furthermore, silicone-based polymers are vulcanised fast at an elevated temperature as well as at room temperature, and are non-flammable, non-toxic, slightly dissipative and temperature-sensitive, and, lastly, highly deformable, which allows for higher magnetostriction and MR effect. However, some issues related to their poor mechanical properties persist. These limitations mainly affect the use of silicone rubbers in most load-bushing applications due to its low strength and shorter fatigue life. However, for some biomedical applications that do not require high-strength materials, silicone-based rubbers are still the most preferred material [121].

To overcome the limitations due to the low strength of silicone rubbers, many investigators have turned their attention to the use of thermosets and thermoplastics polymers due to the wide range of mechanical properties that can be achieved by simply modifying the type of concentration of the constituent elements.Another alternative to the use of silicone-based rubbers for the fabrication of MREs is natural rubber, which generally have 
better mechanical properties and heat resistance. In particular, the use of natural rubber as matrices for MREs shows advantages, such as a good resistance to tearing at high temperatures and good dynamic performance. However, the use of natural rubber for MREs matrices present some disadvantages. The manufacturing of natural-rubber based matrices is much more complex than the fabrication using silicone-based rubbers, due to the raw material of the matrix being in solid state, which requires specialised equipment [122].

If the basic mechanical properties of MREs are given by the polymeric matrix, magnetic particles give these materials their field dependent properties. The shape, size and composition of these magnetic particles are factors that influence the behaviour of the resulting MRE. Regarding the shape of these magnetic particles, the most used particles are of spherical shape, since they are widely commercialised, while the size of the particles can vary. However, most CIPs reported in the literature have a size smaller than $10 \mu \mathrm{m}$. The reason why smaller sizes are preferred is that smaller particle sizes lead to a higher effective area of interfacial friction between the particle and the matrix [123]. Regarding the composition, it influences the way particles behave in the presence of and without an external magnetic field, where soft magnetic particles and hard magnetic particles can be distinguished.

Soft magnetic particles are particles of low-coercivity ferromagnetic materials, or softmagnetic materials, such as iron and iron oxides. These soft-magnetic materials can develop strong magnetisation along the applied magnetic field, but do not stay magnetised after the external magnetic field has been removed (low-coercivity). Therefore, soft magnetic particle-based MREs magnetorheological effect and magnetostriction effect are due to the attraction or repulsion forces of the induced dipole in the soft-magnetic particles by the magnetic field. Carbonyl iron powders (CIPs) are the most widely used magnetizable particles. CIPs use for MRE fabrication is widespread due to their properties: their high magnetic saturation and permeability allows for a high MR effect and magnetostriction, while their low coercivity means that they do not have high magnetic remnant properties, which allows for the mechanical properties of the material to return to normal once the external magnetic field is no longer present.

Hard magnetic particles are those formed by high-coercivity ferromagnetic materials [124]. These materials' high-remnant characteristics allow them to retain high residual magnetic flux density, which means that they exert a magnetic force, even in the absence of magnetic fields, once they are magnetically saturated. The most widely used "hard magnetic" material for magnetic particles is neodymium-iron-boron (NdFeB). In this case, the magnetorheological effect or the magnetostriction is achieved not only by the dipoledipole interactions of the particles under a magnetic field, but also by the torque induced on these magnetised particles by the external magnetic field. For the magnetic field to produce an optimal torque on the particles, these must be aligned in the matrix.

\subsubsection{Fabrication of Magnetorheological Elastomers}

The synthesis of MREs includes the conventional methods for elastomers fabrication, as well as novel methods, such as $3 \mathrm{D}$ printing. In this section, we will focus on the conventional methods. In them, the mixture of magnetic particles and the matrix material is crosslinked, cured or vulcanised in a mould. Therefore, magnetizable particles stay locked within the polymeric network after the mixture is completely crosslinked. The mould defines the dimensions, such as the thickness and width of an MRE to be developed [121]. A new step arises in the fabrication of MREs as the disposition of the magnetic particles inside the matrix can be defined in the curing process. In the presence of a magnetic field during the curing process, the magnetic particles are oriented and aligned in the direction of the magnetic field, and the resulting MRE has an oriented, anisotropic structure consisting of chains of particles. MREs cured without the magnetic field results in a welldispersed distribution of particles with no particular orientation and, therefore, the result is an isotropic structure. Apart from the presence of a magnetic field during the process of curing, the distribution of magnetic particles in MREs is influenced by many factors, 
such as the interaction forces between particles (in the case of hard-magnetic particles), sample size, volume fraction of particles and temperature. However, while understanding the influence of these factors during MRE fabrication is important, it is extremely difficult for experimental and computational methods.

\subsubsection{Magnetorheological Elastomers in Soft Robotics}

One of the most widespread uses of MREs is in the field of soft robotics. This field is centred in the study of different mechanisms and materials for controlling and fabricating robots able to perform tasks inaccessible to traditional rigid robots. One of the main challenges of soft robotics involves robot tethering, which is the dependence of a robot on a base for the supply of a form of actuation, which may be electrical, hydraulic, etc. MREs pose as a promising candidate for soft robotics due to the nature of magnetic actuation, which is completely remote. For example, by controlling the magnetic alignment of different domains of 3D printed MEs, an external magnetic field was used to induce specific deformation onto these bodies to achieve complex remote manipulation and repeatable movements [125]. Other soft robots of millimetre-size were able to rotate, swim and roll by varying the intensity and direction of the applied magnetic field. In biomedical applications, a long soft robot with a MRE "head" was remotely guided through an intricate path using EMFs [126]. In the case of soft robotics, hard magnetic particles are mostly used, due to the way magnetic forces are translated into the MRE. In this case, since locomotion is the main goal, a higher magnetostriction effect is achieved by using hard particles with a certain orientation. These particles, under the influence of a magnetic field, tend to align with it achieving fast and large deformations.

\subsubsection{Magnetorheological Elastomers as Dynamic Cell Culture Substrata}

Mechanical cues are transformed into intracellular signals in a process known as mechanotransduction. These mechanical cues, such as ECM strain and elasticity have an important influence on different processes, such as cellular proliferation and migration. Altered tissue biomechanics appear to play a role in several diseases and disorders, such as cancer or chronic ulcers.

Many attempts have been made to replicate the substrate's different mechanical conditions and how it affects cell behaviour. However, most of these attempts involve the fabrication of static substrates with a known stiffness (by mixing different ratios of PDMS and curing agent, for example [127] or the fabrication of substrates with stiffness gradients [128]. Other attempts have been made at the fabrication of dynamic substrates, such as thermoresponsive polymers [129], electro-active monolayers or piezo-controlled substrates [130]. However, these methods are either applied in situ or have a direct effect on cell culture. In this regard, magnetoactive elastomers pose as an interesting candidate for emulating these varying mechanical cues. They allow for remotely tuning the mechanical properties of a material by the application of an external magnetic field, which is almost undetected by the biological tissue or culture due to their low magnetic permeability. In this line of work, [131] developed a cell culture substrate based on ultra-soft PDMS embedded with carbonyl iron powder with tuneable mechanical properties, which can alter cell functions and induce surface translocations. The authors of [115] developed another kind of magnetically controlled substrate for cell culture, based on magnetic micro-pillars embedded in a polymeric matrix for the study of mechanotransduction mechanisms in single cells. In a recent article, Garcia-Gonzalez et al. [132] discuss the potential application of MREs as smart substrate for epithelial cellular systems.

\subsection{Magneto-Active Hydrogels}

In the field of smart polymeric materials, magnetic interaction is an especially good candidate for actuation due to its biocompatibility, even at relevant high fields, as well as to the fact that magnetic fields can provide this actuation in a remote manner [133]. Hydrogels capable of responding to the absence or presence of a magnetic field are known as 
magneto-responsive hydrogels. These are composed by inorganic magnetic nanoparticles (MNPs), which are physically entrapped in a hydrogel (by using the blending method or in situ precipitation method), or covalently immobilised to a hydrogel network (by using the grafting onto method). Magnetoactive hydrogels are, therefore, the combination of hydrogels with micro- and/or nano-sized magnetic particles that can quickly respond to an external magnetic field (EMF) [134].

Fabrication Techniques

Ferrogels can be manufactured by different methodologies, among them:

(i) Blending Method (Figure 2A) MNPs and hydrogels are prepared separately in a sequential order. The prepared MNP sediment is then dispersed in an aqueous or oil phase (i.e., a ferrofluid) to avoid oxidisation and aggregation. Finally, the mixture of the ferrofluid and the hydrogel precursor solution are crosslinked, resulting in the encapsulation of the MNPs in the hydrogel. The main advantage offered by the blending method is the simplicity of the process. Furthermore, both components necessary for the fabrication are commercially available. Another advantage is the fact that both components are prepared separately, which offers the possibility to achieve a uniform particle size in hydrogels over a wide range from nanometres to micrometres, whether by adjusting the concentration of the reactants, the stirring speed, and the preparation cycle, or by purchasing the desired MNPs. However, it is challenging to achieve a uniform MNP distribution within the hydrogels, and MNPs may diffuse out of the magnetic hydrogels when immersed in a liquid solution [134].

(ii) In Situ Precipitation Method (Figure 2B) In the in situ precipitation method, the hydrogel networks act as a chemical reactor. An inorganic salt with iron ions reacts with precipitating agents to generate MNPs inside the hydrogel polymeric network. Firstly, hydrogels are fabricated via temperature change, radical polymerisation, or a photo-crosslinking reaction. Secondly, the hydrogels are placed into a concentrated aqueous solution containing $\mathrm{Fe}^{2+}$ and $\mathrm{Fe}^{3+}$, and the ferrous ions are taken at a molar ratio of 1:2 until swelling equilibrium is reached. Finally, the swollen hydrogels with absorbed $\mathrm{Fe}^{2+}$ and $\mathrm{Fe}^{3+}$ are immersed into an alkali solution for MNP precipitation. The in situ precipitation method has several advantages in the fabrication of magnetic hydrogels. Firstly, many inorganic particles can be introduced into the hydrogel network, ensuring that colloidal-sized particles can be well dispersed in the matrix. Secondly, the preparation process is simple and low-cost. However, the in situ precipitation method is only suitable for specific hydrogels with a stable network, otherwise the hydrogel network may be destroyed by alkali solution during the preparation process [134].

(iii) Grafting-Onto Method (Figure 2C) In the grafting-onto method, covalent bonds are formed between the hydrogel network and the MNPs. These covalent bonds are achieved by grafting several functional groups onto the surface of the MNPs, which work as nano-crosslinkers to form a covalent coupling with the monomers when polymerised. The main advantage offered by the grafting-onto method deals with the problem of particle diffusion into the media. Both previous methods consisted of a physical encapsulation of the particles. With this method, the direct covalent coupling between the hydrogel matrix and the magnetic particles leads to a more permanent particle encapsulation. However, the grafting of the functional groups onto the magnetic particles is a difficult task with a long preparation cycle and high cost, which makes this method a complex fabrication process [134]. 
A

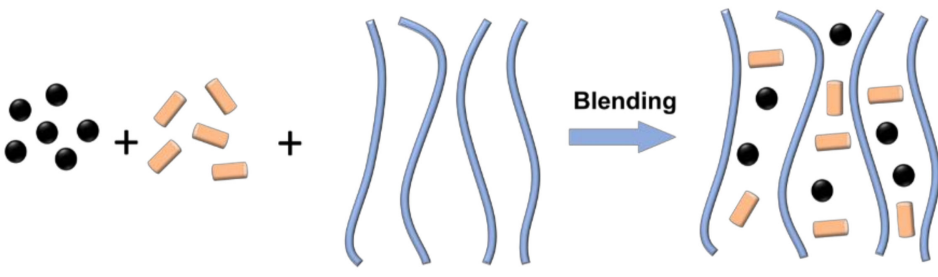

B
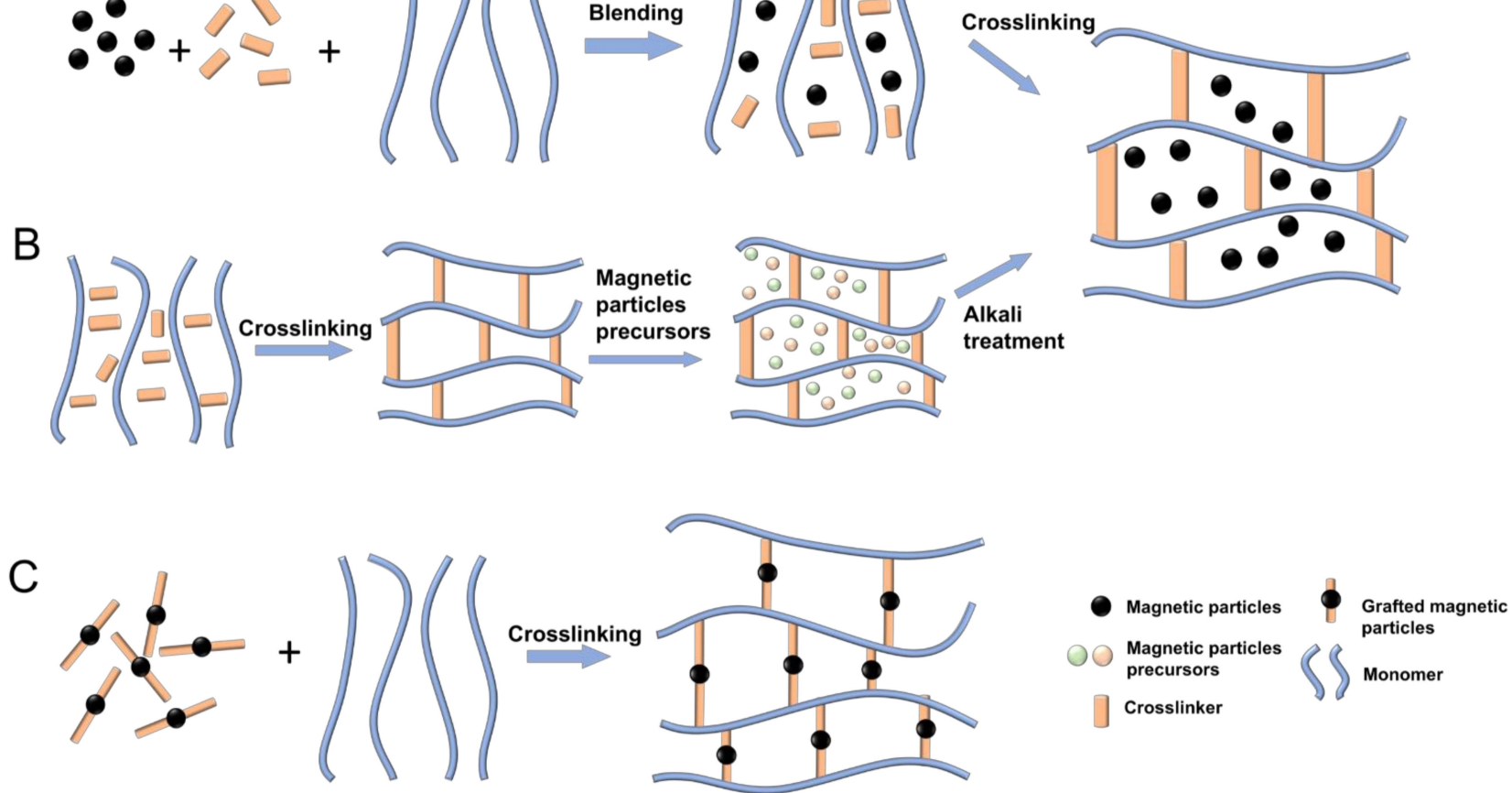

Figure 2. Scheme of different manufacturing techniques for magneto-active hydrogels or ferrogels: (A) blending method; (B) in situ precipitation method; (C) grafting-onto method.

\subsection{Three-Dimensional Printing of Magneto-Active Polymers}

In recent years, additive manufacturing technologies, mainly 3D printing, have been posed as a good candidate for the fabrication of sophisticated structures, and allows for a low-cost, time saving and customizable result. However, 3D printed objects were always static [135]. A new concept has recently appeared, considering the design and fabrication through 3D printing technologies of structures that may undergo a structural change when subjected to an intended stimulus. This concept, known as $4 \mathrm{D}$ printing, was first introduced by professor Tibbits as a new design of a complex spontaneous structure that changes with time as a response to a stimulus after the manufacturing process is completed [136]. Another important characteristic of $4 \mathrm{D}$ printed structures is the ability to revert to their original status [135]. Four-dimensional printing takes common features from 3D printing for the design and generation of the structure but controls a specific multifunctional response of the printed materials, thus programming the mechanical response to diverse stimuli. For example, some materials respond to temperature, light or a magnetic field through different mechanisms [137]. Magneto-active soft materials (MASM) are shapeprogramable active materials capable of controlled and intended shape transformation and object locomotion. These changes in structure or displacement of the materials are achieved in a remote manner through the application of a magnetic field, which offers numerous potential applications in the fields of soft robotics and biomedicine, amongst others [138].

There exist many approaches to additive manufacturing, such as fused deposition modelling (FDM) for thermoplastics, or stereolithography (SLA) for photocurable resins. However, one of the main techniques employed for the fabrication of MASMs is direct ink writing (DIW) [139]. This technique consists of the injection of a layer of material through a nozzle using either mechanical or pneumatic actuation. This material then undergoes polymerisation, allowing for the deposition of the next layer on top of the previous one. The stacking of these layers then leads to the final product. The other main technique used for printing of magnetic polymers is vat photo-polymerisation (VPP), which includes techniques such as SLA or digital light processing (DLP) [140]. These techniques consist in the polymerisation of a photo-crosslinkable resin. In this case, the differences between SLA 
and DLP lie on the area affected by the light source. In the case of SLA, a laser irradiates a path that will be crosslinked, while in DLP, the light source projects a whole image onto the vat, crosslinking the whole layer at once. In both cases, the fabrication is done layer by layer. These two techniques for the fabrication of MASMs are widely used for the ease of dispersion of the magnetic fillers in the polymeric matrix, which can be in a liquid state prior to printing in both cases [141]. This fluid nature of the printing material also allows for the orientation of the magnetic fillers prior to polymerisation, by application of a controlled magnetic field.

Regarding MREs, some work has been developed in recent years concerning the printing of these materials. DIW, together with the application of controlled magnetic fields during the printing process, was employed by Sidersberger et al. [142] to obtain functional materials with a desired distribution of magnetic particles within the polymeric matrix. This process consisted in the application of a desired magnetic field during the printing process to achieve the free displacement of the magnetic filler particles within the printed matrix prior to its polymerisation. This procedure was described, accounting for six printing degrees of freedom, due to the capability of the magnetic particles to move freely and controllably throughout the polymeric matrix. Another notable example of $4 \mathrm{D}$ printing of magneto-active materials was carried out by Kim et al. [125]. In this case, the fabrication of fast-transforming structures was achieved by DIW of a silicon matrix filled with neodymium-iron-boron $(\mathrm{NdFeB})$ hard magnetic particles. These particles were oriented at the extrusion nozzle by using an electromagnet at the tip of the dispenser, capable of applying an oriented magnetic field. This way, the extruded material had a magnetic orientation, which was then used to achieve fast transformation of the structure by application of a magnetic field. Another example of soft magneto-active polymers printing was explained by Ji et al. [143]. In this case, they used soft $\mathrm{Fe}_{2} \mathrm{O}_{4}$ magnetic particles dispersed in a modified polyethylene glycol and cyclic trimethylolpropane formal acrylate photocurable resin to print, using DLP, different structures combining magnetic and not magnetic regions. These structures were able to achieve bending, deformation and cargo transportation. All these examples of printed magneto-active soft polymers serve as a proof-of-concept of an exciting technique and its application in the field of soft robotics bioengineering.

Regarding magneto-active hydrogels, the main objective for these materials is their use as soft actuators capable of working inside the human body, for specific biomedical applications. In this regard, Tang et al. [144] developed a complex structure through 3D printing capable of undergoing volume collapse due to the magnetothermal effect. Using $\mathrm{Fe}_{3} \mathrm{O}_{4}$ magnetic particles dispersed in a poly(N-isopropylacrylamide) (PolyNIPAm), they developed a shape transformative structure capable of encasing and killing cancer cells through hyperthermia. Another example was developed by Zhu et al. [145]. In this case, they were able to print, using a rapid 3D printing technology (microscale continuous optical printing), poly(ethylene glycol) diacrylate (PEGDA)-based biomimetic microfish with embedded $\mathrm{Fe}_{3} \mathrm{O}_{4}$ magnetic particles. These microfish were able to propel through an aquatic environment, and were magnetically guidable, which proved to be a viable approach for drug delivery and toxin neutralisation systems.

\subsection{Metabolism of MAPs}

The application of MAPs in the biomedical field carries the need to study the biocompatibility and degradability of these materials inside the body. The matrix material can be chosen so that its biocompatibility is ensured, and its degradability controlled. Many studies have been carried out to test the biocompatibility of materials, such as (poly)lactic acid, (poly)ethylene glycol or collagen hydrogels [146]. However, regarding the magnetic particles, other factors are to be taken into consideration regarding their biocompatibility, such as structural properties, dosage and chemical composition [147]. For example, some materials are known to be toxic for biological environments and are therefore not suitable for biomedical applications, such as cobalt, nickel, cadmium, zinc and silver, while others 
such as titanium or iron oxide-based particles are considered relatively safe to cells [147,148]. In addition, the location of the particles with respect to the cells can also play a role in the biocompatibility of these materials since the internalization of MNPs could invoke a cytotoxic response [149]. Furthermore, the structural properties of the MNPs, such as particle size and shape, may also influence the response of the organism to their presence. Different particle shapes can contribute to their aggregation and coagulation, while their size is a determining factor on their spatial arrangement [147]. In detail, particles smaller than $5.5 \mathrm{~nm}$ can be quickly removed through the kidney [150], particles up to $200 \mathrm{~nm}$ can be sequestered by phagocytes of the spleen [151], and particles larger than $5 \mu \mathrm{m}$ can be cleared via the lymphatic system [152].

\section{Theoretical and Computational Mechanical Frameworks for Magneto-Active Polymers}

The complex nature of MAPs hinders the complete understanding of their mechanical response to external magnetic stimuli and, eventually, to coupled magneto-mechanical loading. This interrelated response depends on so many factors, such as magnetic properties and distribution of the particles, nonlinear mechanical response of the polymeric matrix, viscous relaxation mechanisms and, in the case of hydrogels matrix, we need to account for solvent diffusion processes as well. Therefore, there are plenty of variables all interacting together that make a full experimental characterisation very challenging and almost unapproachable. One alternative to overcome some of these limitations is to complement experimental research with theoretical and computational models. These models allow for: (i) evaluating the spatial and temporal distribution of mechanical variables such as strain and stress; (ii) reducing the number of experimental tests and the associated costs. In this regard, the modelling of MAPs is highly complex and needs of multiphysics and multiscale approaches.

This section presents some of the most relevant models in the current literature to describe the magneto-mechanical behaviour of MAPs. To this end, we first introduce some hyperelastic-based models to define the mechanical response of the polymeric matrix. Then, we present magneto-mechanical coupled approaches to model MAPs from two different perspectives: based on microstructural features and on the macroscopic homogenised behaviour. Finally, we provide an overall view on the modelling of magneto-active hydrogels accounting for mechanics, magnetics and diffusion processes at once.

\subsection{Constitutive Modelling of Polymeric Matrix}

The mechanical response of soft polymers is highly nonlinear, dependent on strain rate and temperature, presents viscous relaxation mechanisms, Mullins' effects and, in the case of hydrogels, relaxation times associated with solvent diffusion. The modelling of elastomers is generally addressed by hyperelastic constitutive laws that are based on an energy potential, $\psi$. This potential depends, a priori, on the deformation gradient tensor $\mathbf{F}$, the material temperature $\theta$, and internal variables (i.e., viscous deformation gradient $\mathbf{F}^{\mathbf{v}}$ for viscoelasticity). This potential corresponds to the Helmholtz free energy and, following thermodynamics principles, can be consistently derived to obtain the final constitutive equations by means of stress tensors.

Some of the most common energy potentials used for the polymeric matrix are the neo-Hookean and eight-chain models, which in their incompressibility form read, respectively, as:

$$
\begin{gathered}
\psi(\mathbf{F})=\frac{G}{2}\left(I_{1}-3\right) \\
\psi(\mathbf{F})=G \sum_{k=1}^{K} \frac{C_{k}}{N^{k-1}}\left(I_{1}^{k}-3^{k}\right)
\end{gathered}
$$

where $G$ is the shear modulus, $I_{1}=\operatorname{tr}\left(\mathbf{F}^{\mathbf{T}} \mathbf{T}\right), \mathrm{N}$ is the number of Kuhn segments and $\mathrm{C}_{\mathrm{k}}$ are constants related to the Padé approximation of the inverse Langevin function. 
These models can be extended to account for viscous responses by defining the potentials as a function of an elastic deformation gradient tensor computed as:

$$
\mathbf{F}^{\mathbf{e}}=\mathbf{F F}^{-\mathbf{v}}
$$

where the viscous component $\mathbf{F}^{\mathbf{v}}$ represents the viscous part of the deformation gradient and is defined by a viscous flow rule. Some examples of viscous-hyperelastic models can be found in the literature [153-155]. Other dependences may include hardeningsoftening terms associated with temperature or continuum damage terms associated with Mullins' effects [156]. Moreover, when the polymeric matrix is composed of hydrogel, a volumetric mechanical response must be added as a consequence of solvent diffusion processes [157-159].

\subsection{Constitutive Modelling of Magnetorheological Elastomers}

Although magneto-active materials (i.e., magneto-active fluids, gels, elastomers) are receiving much attention in recent years, the fundamentals of the mathematical modelling of their magneto-mechanical coupled behaviour were established half a century ago. The first referential works are due to Pao and Nemat-Nasser [160], Eringen and Maugin [161], Maugin [162]. Since then, and with an increase in activity during last few years, different constitutive models have been proposed. According to the nature of such models, we can classify them into two main groups: (i) continuum models that describe the macroscopic homogenised behaviour of MAPs (mainly based on phenomenological concepts); (ii) micromechanical constitutive models that base their formulation of microstructural features of the MAP composites. Next, we present the main works of each type and their evolution during the last decade.

\subsubsection{Continuum-Based Models}

Some of the seminal works are due to Dorfmann and Ogden $[156,163]$. In these works, the authors established the fundamentals to develop magneto-mechanical formulations for finite strains, solving analytically some classical boundary value problems. In this regard, they proposed a general free energy, depending on both mechanical (i.e., deformation gradient tensor $\mathbf{F}$ ) and magnetic variables. Regarding the magnetic variables, there are three main quantities that, expressed in the spatial configuration, read as the magnetic field $\mathbf{h}$, magnetisation $\mathbf{m}$, and magnetic induction $\mathbf{b}$. These variables can be alternatively expressed in the material configuration, respectively, as:

$$
\begin{gathered}
\mathbf{H}=\mathbf{h F} \\
\mathbf{M}=\mathbf{m F} \\
\mathbf{B}=\operatorname{det}(\mathbf{F}) \mathbf{b F} \mathbf{F}^{-\mathbf{T}}
\end{gathered}
$$

Moreover, these variables are related in the bulk as:

$$
\mathbf{B}=\operatorname{det}(\mathbf{F}) \mu_{\mathrm{o}} \mathbf{C}^{-1}(\mathbf{H}+\mathbf{M})
$$

where $\mu_{\mathrm{o}}$ is the vacuum magnetic permeability.

Similar to the calculation of the stress tensors from thermodynamic principles in hyperelasticity, the mechanical and magnetic constitutive equations can be derived from the total energy potential as, for example:

$$
\begin{aligned}
& \mathbf{P}=\frac{\partial \psi(\mathbf{F}, \mathbf{M})}{\partial \mathbf{F}} \\
& \mathbf{B}=\frac{\partial \psi(\mathbf{F}, \mathbf{M})}{\partial \mathbf{M}}
\end{aligned}
$$


where $\mathbf{P}$ is the first Piola-Kirchhoff stress tensor. It is worth mentioning that the magnetic problem allows for taking any magnetic variable as the independent one, which choice will be determined by the specific application.

Therefore, these constitutive equations, along with the corresponding governing equations, provide a general framework for magneto-active elastomers. The main governing equations are the mechanical balance and magnetostatics Maxwell's equations:

$$
\begin{gathered}
\nabla \cdot \mathbf{P}+\mathrm{f}_{\mathrm{o}}=0 \\
\nabla \cdot \mathbf{B}=0 \\
\nabla \mathbf{x H}=0
\end{gathered}
$$

where $\nabla$ is the material gradient and $\mathrm{f}_{\mathrm{o}}$ is the external mechanical body forces.

From these bases, other authors have proposed significant advances including other features. In this regard, Bustamente and co-workers [164] extended this framework to account for the underlying transverse isotropy of certain MAPs. Moreover, one limitation of these previous models was that the polymeric matrix is, by nature, a viscoelastic material. Therefore, the MAP composite will show time-dependent responses, such as strain rate dependence or relaxation mechanisms. These issues were addressed by Saxena et al. [165] and Nedjar [166], who included viscoelastic behaviours. Very recently, Zhao et al. [124] proposed a constitutive model to describe the response of soft MAPs reinforced with hard magnetic particles, and Garcia-Gonzalez [167] extended this framework to incorporate time-dependent responses.

\subsubsection{Micro-Mechanical-Based Models}

Compared to continuum approaches, the micro-mechanical-based models overcome an important limitation: the consideration of detailed microstructural information, such as the magnetic particles distribution within the polymeric matrix. These micro-mechanical models allow to account for the specific arrangement of the magnetic particles and, then, the magnetic interactions between particles, and with the surrounding matrix. This is an important consideration as the relative position between particles determines the nature of the internal magnetic forces, i.e., attraction or repulsion. The most common assumptions for these models are a purely isotropic distribution of the particles and an anisotropic distribution, forming perfectly aligned chain-like structures [154]. However, experimental evidence show that more complex arrangements are likely to be formed within the matrix [168].

Regarding the modelling fundamentals of the micro-mechanical approaches, these explicitly consider the magnetic interactions between the particles that are embedded into the polymeric matrix. These internal magnetic interactions are the primary driver of geometrical changes in the MAP and mechanical properties variations under magnetic stimuli. A pioneering work is due to Jolly et al. [169], where the authors developed a one-dimensional lattice model. More recently, Ivaneyko and co-authors [170] extended the latter model to predict the mechanical response of MAPs to a magnetic stimulus by means of variations in stiffness, contraction and expansion mechanisms. More recently, GarciaGonzalez and Hossain [154] extended these approaches to finite deformations adding viscoelastic responses and considering a wide range of magnetic particle distributions. The common fundamental behind these models is the consideration of a magnetic contribution to the energy potential describing dipole-dipole interactions as:

$$
\psi_{\text {magnetic }}(\mathbf{F}, \mathbf{M})=-\frac{1}{\mathrm{~V}_{\mathrm{o}}} \frac{\mu_{\mathrm{o}}}{4 \pi} \sum_{i j}\left[\frac{3\left(\mathbf{m}_{\mathbf{d i}} \cdot \mathbf{r}_{i j}\right)\left(\mathbf{m}_{\mathbf{d i}} \cdot \mathbf{r}_{i j}\right)}{\mathbf{r}_{i j}{ }^{5}}-\frac{\left(\mathbf{m}_{\mathbf{d i}} \cdot \mathbf{m}_{\mathbf{d j}}\right)}{\mathbf{r}_{i j}{ }^{3}}\right]
$$

where $\mathrm{V}_{\mathrm{o}}$ is the reference volume of the MAP, $\mathbf{m}_{\mathbf{d i}}=\mathrm{v}_{\mathrm{p}} \mathbf{M F}^{\mathbf{T}}$ is the dipole moment of the $\mathrm{i}$-th particle with $\mathrm{v}_{\mathrm{p}}$ being the particle volume, and $\mathbf{r}_{i j}$ represents the current distance 
between i-th and $j$-th particles. Note that the dependence with $\mathbf{F}$ is implicitly accounted in $\mathbf{r}_{i j}$, as these distances changes with the material deformation.

In Figure 3 (adapted from [154]), we present a scheme with the main features of a micromechanical-based model and how these approaches can be scaled up to describe the macroscopic response of MAPs, while keeping relevant information from the microstructure.

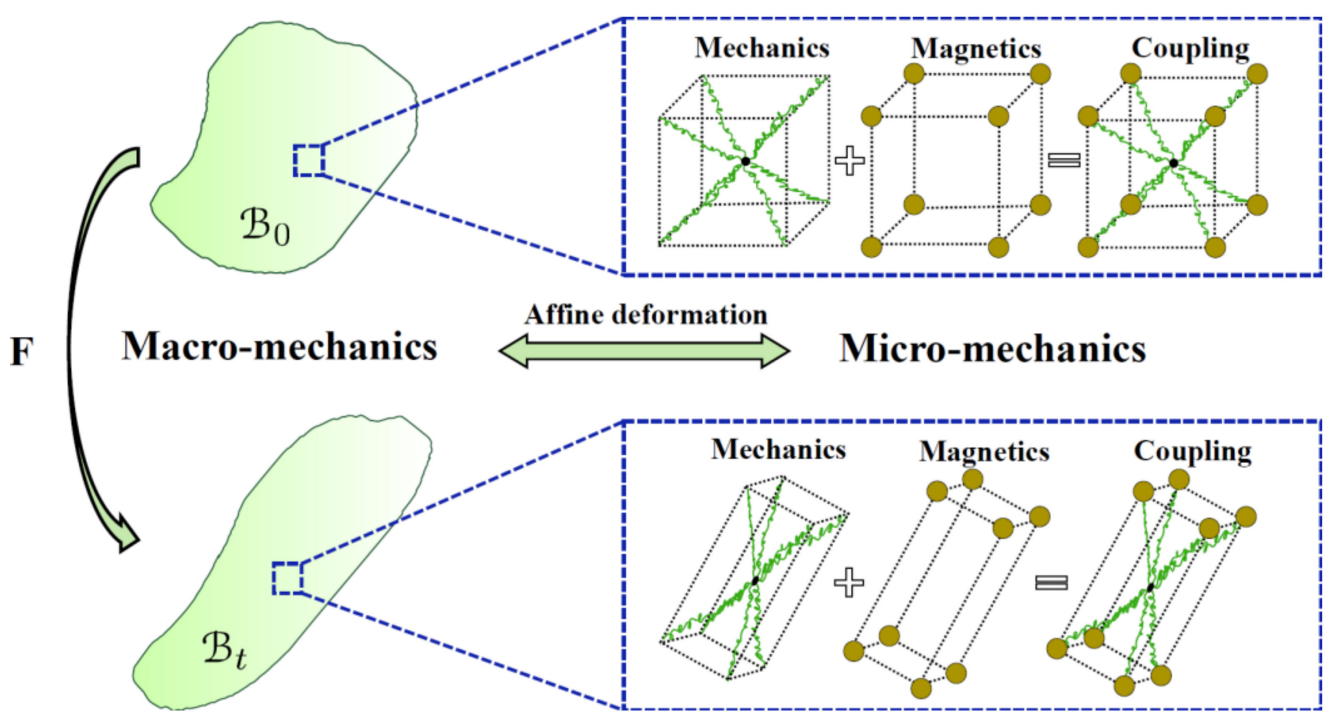

Figure 3. Scheme of microstructural-based approach, accounting for both magnetic particles and polymer matrix components, and how these models can be scaled up to the micromechanical level. Figure adapted from Garcia-Gonzalez and Hossain [154].

Alternative to these models, other micro-mechanical-based approaches propose variationally consistent phase-field theories [154], microstructurally guided explicit continuum models [171,172], or $\mathrm{FE}^{2}$ computational frameworks [173]. These approaches allow for considering further important features, such as heterogeneous magnetic fields within the MAP, or the explicit interaction between the particles and the matrix. However, they usually introduce much higher computational cost.

\subsection{Constitutive Modelling of Magneto-Active Hydrogels}

When modelling MAPs using a hydrogel as polymeric matrix (magneto-active hydrogels, MAHs), to the already complex problem presented in the previous section, we need to incorporate a solvent diffusing within the system formed by the polymeric network and magnetic particles. This feature implies that, along with the mechanical and magnetic problems, we will have a solvent diffusion process occurring in parallel. This diffusion will directly interplay with the mechanical behaviour of the MAH by incorporating a volumetric response due to the incompressibility condition of the solvent. Therefore, the volumetric mechanical stress of the MAH will be determined by the amount of solvent within the polymeric network that, in turn, will temporarily diffuse influencing the mechanical balance. Overall, the MAH system combines multiple difficulties associated with nonlinearities and coupled responses at different time scales. The short-time response of these materials presents strain rate dependences that determine the nonlinear instantaneous mechanical response [174,175]. After this initial response, the polymeric network experiences a viscoelastic relaxation process resulting in a continuous decrease in stiffness until complete relaxation $[174,176,177]$. Then, as a long-time response, the mechanical deformations within the MAH lead to heterogeneous distribution of solvent concentration that evolve via solvent diffusion process $[178,179]$. In addition, note that these diffusion-mechanical processes are also constantly affected by the interaction between magnetic particles with the external magnetic field. An overall description of the mechanics, magnetics and diffusion process interplays is shown in Figure 4 (adapted from [157]). Here, an MAH is considered 
with a given initial swelling ration. When this is immersed in a solvent, solvent diffusion occurs until reaching a stable swelling ratio. Then, a magnetic field is applied, leading to mechanical deformation due to magnetostriction response. Such a mechanical deformation results into a heterogeneous distribution of the solvent concentration which, in turn, leads to a continuous solvent diffusion until reaching a new stable state.

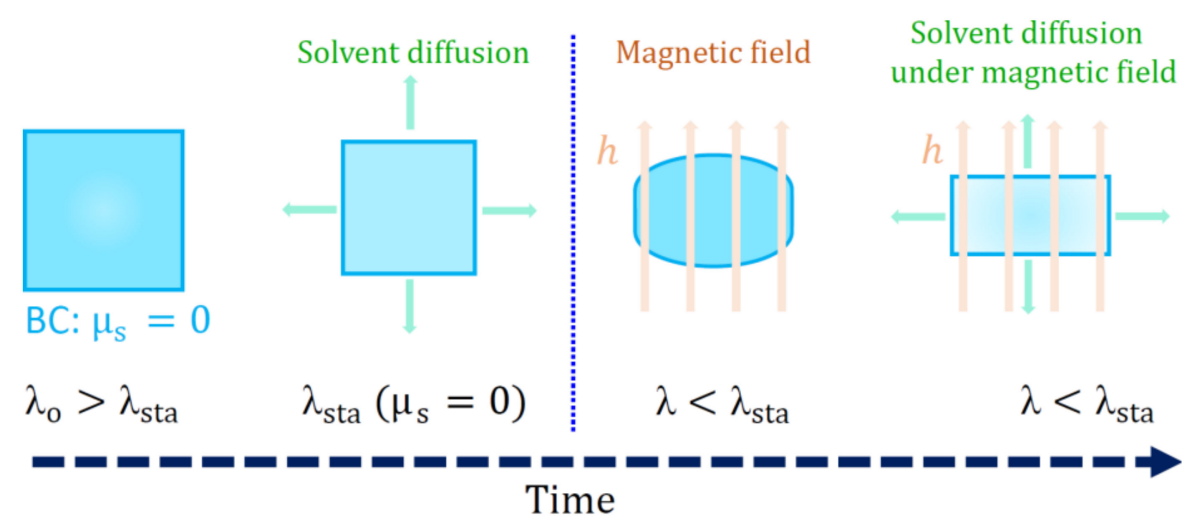

Figure 4. Stages of the deformation process of an MAH surrounded by a solvent with null chemical potential $\left(\mu_{\mathrm{s}}=0\right)$ and exposed to an external magnetic field. The MAH experiences, in a timeline: (i) initial swelling ratio $\lambda_{\mathrm{o}}$; (ii) solvent diffusion until reaching a stable swelling ratio $\lambda_{\text {sta }}$; (iii) application of an external magnetic field $h$; solvent diffusion until reaching a new stable state. Figure adapted from Garcia-Gonzalez and Landis [157].

Therefore, the complete modelling of MAHs needs to account, in a coupled manner, for magnetics, solvent diffusion, and mechanics. A seminal work by Hong and co-authors [158] proposed a nonequilibrium theory for coupled diffusion and finite deformations. Further extensions of this theory are due to Zhang et al. [180], Lucantonino et al. [181] and Bouklas et al. [182]. More recently, viscoelasticity has been included in these modelling frameworks [183]. In recent years, diffusion-mechanical theories have been coupled to the magnetostatics problem. In this regard, the governing equations presented in Section 5.2 complement the diffusion equation:

$$
\frac{\partial c_{s}}{\partial t}+\nabla \cdot J^{s}=r^{s}
$$

where $c_{s}$ is the solvent concentration, $\mathbf{~}^{\mathrm{s}}$ is the nominal flux of the solvent, and $\mathrm{r}^{\mathrm{s}}$ is a source term for the number of solvent molecules injected into unit reference volume per unit time. Now defining the total energy potential, depending on the solvent concentration as well, $\psi\left(\mathbf{F}, \mathbf{M}, \mathrm{c}_{\mathrm{S}}\right)$, from thermodynamic principles, this solvent concentration can be related to a chemical potential $\left(\mu_{\mathrm{s}}\right)$ as:

$$
\mu_{\mathrm{s}}=\frac{\partial \psi\left(\mathbf{F}, \mathbf{M}, \mathrm{c}_{\mathrm{s}}\right)}{\partial \mathrm{c}_{\mathrm{s}}}
$$

Following these ideas, Liu and co-authors [184] developed a constitutive model coupling mechanical, magnetic, and chemical fields. This work was extended by the authors to study drug-delivery systems based on MAHs [185] and to incorporate $\mathrm{pH}$ sensitivity [186]. In addition, Gebhart and Wallmersperger [187] developed a model for MAHs based on Biot's consolidation theory. More recently, these frameworks were extended to incorporate time-dependent responses in the constitutive formulation of MAHs to study their effects across different time scales by Garcia-Gonzalez and Landis [157].

\section{Magneto-Active Polymers in Biomedical Applications}

The conceptualisation of novel stimuli-responsive biomaterials constitutes one of the major challenges in materials science today. These multifunctional materials own the capability of sensing changes in their environment, process the information and actuate 
to that stimulus [188]. As introduced in the previous sections, MAPs stand out among smart polymers because of their ability for modifying their spatiotemporal response under an external magnetic field [188-190]. This feature makes them very interesting for biomedical applications in drug delivery [191,192], tissue engineering [192,193], cancer therapy [144], [188,191,194-197], or neuronal repair [189,192,198]; see Figure 5. Despite these promising applications, conflicting reports in the literature $[189,199]$ have opened questions on cytotoxic effects that need to be answered. Next, we present the most promising applications of MAPs within the biomedical sector.

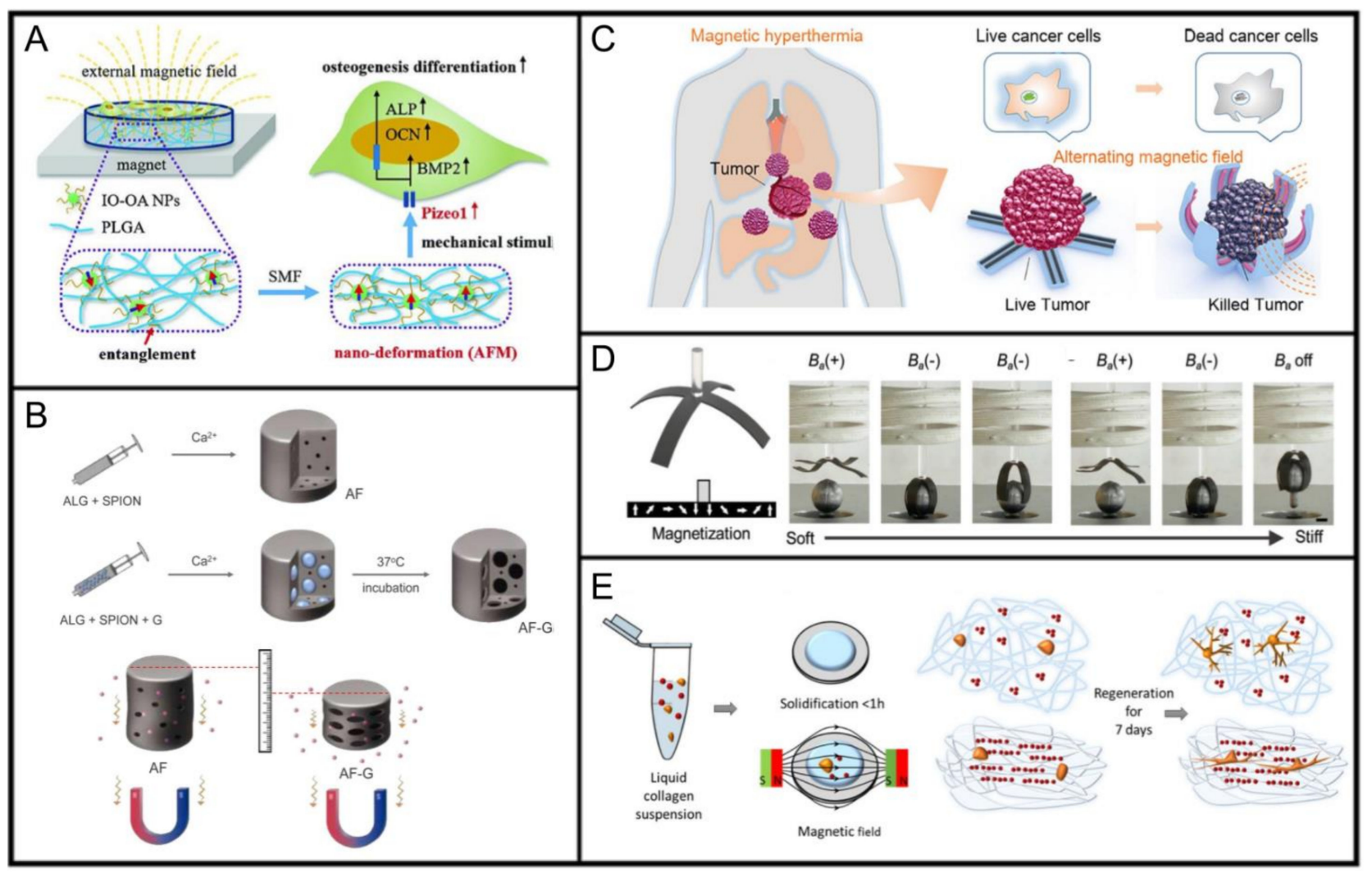

Figure 5. Bioengineering applications of magneto-active polymers in: (A) bone tissue engineering: mechanical stimulation based on the deformation of a magnetic composite leads to enhanced osteogenic differentiation (adapted with permission from [193]); (B) drug delivery: alginate ferrogel deformation by application of a magnetic field leads to controlled drug release (adapted with permission from [191]); (C) hyperthermia treatment: application of a magnetic ferrogel (PNIPAm$\mathrm{Fe}_{3} \mathrm{O}_{4}$ ) for tumour encasing and hyperthermia cancer therapy (adapted with permission from [144]); (D) soft robotics (adapted with permission from [190]); (E) neuronal regeneration: remote magnetic orientation of collagen fibres in a hydrogel for directed neuronal regeneration (adapted with permission from [198]).

\subsection{MAPs for Bone and Tendon Tissue Engineering}

MAP systems present unique characteristics that make them ideal candidates for application in tissue regeneration. For instance, a current challenging problem is the repair of large bone injuries due to trauma, tumour removal or diseases, such as osteoporosis. During the bone regeneration process, scaffolds play an important role, providing adequate biological environment and promoting cell adhesion, proliferation and differentiation $[189,200]$. These scaffolds must comprise at least two properties: biocompatibility and degradability [201]. Conceptualising magneto-active scaffolds allows for remote mechanical stimulation transmitting forces to the cells or altering the mechanical properties of the surrounding environment, thus promoting better bone regeneration $[189,201]$. To this end, magnetic-induced changes in their properties can simulate load bearing in healing bone or tendons, where actual loads cannot be applied but are still essential to the correct 
differentiation and repair of these structures. Previous studies have reported that they can overexpress osteogenic markers and activate vascular differentiation [202,203]. One of the first attempts of using magnetic hydrogels for tissue engineering was the creation of aligned collagen-fibrils hydrogels by the addition of streptavidin coated magnetic beads. By the application of an external magnetic field (EMF), aligned collagen fibrils were obtained in both plain and cell-bearing gels, at least a few millimetres thick [204]. Based on this idea, Tampieri et al. [205] developed a novel approach, which included the incorporation of MNPs to hydroxyapatite (HA) scaffolds directly during the HA nucleation. This means that the MNPs become an intrinsic component of the scaffold. The fabrication of these scaffolds, with gradients in magnetisation and mineralisation, created a novel model for osteochondral differentiation. Bock et al. [206] developed a magnetic scaffold by dip-coating a conventional HA/Coll scaffold for bone tissue engineering in a ferromagnetic fluid. By this technique, the porosity of the scaffolds allows the ferrofluids to be drawn inside the structure by capillarity. These scaffolds were shown to be able to maintain cell culture with no observable effect on the morphology or survivability of the cells. Silva et al. [207] used a photocrosslinkable magnetic hydrogel made of methacrylatechondroitin sulphate (MA-CS) enriched with platelet lysate, with encapsulated MA-CS coated iron-based magnetic particles. EMF application modulated the swelling degradation and release of PL-derived growth factors and impacted both cell morphogenesis and expression and synthesis of tendon- and bone-like matrices. Karagiorgis et al. [208] reported the synthesis of collagen-based nanocomposite hydrogels with tuneable properties. The technique used for the magnetisation of the hydrogel was the dip-coating of the scaffold on a ferrofluid of hydrophilic magnetite nanoparticles. A study was carried out on the morphology, composition, magnetic properties and mechanical response of the scaffold. Fernandes et al. [209] showed that the application of an external magnetic field to magneto-active scaffolds induced pre-osteoblast proliferation, attributed to both local magneto-mechanical and magneto-electrical responses of the scaffold. Henstock et al. [210] tried a novel approach for force transmitting to cells. They created a magnetic hydrogel by attaching MNPs directly to the mechanically activated TREK1k+ receptor of human mesenchymal stem cells. By the application of an oscillating EMF, mechanotransduction was stimulated and hydrogels showed a 2.4-fold increase in mineralisation.

Regarding tendon and cartilage tissue engineering, multiple advances have been made regarding magnetic scaffolds. Due to the limitation of self-repair from articular cartilage, a great deal of efforts has been employed to overcome this limitation and deal with articular cartilage injury. The focus of cartilage tissue engineering lays on the ability of different materials to properly recruit bone mesenchymal stem cells, and to support their activity to promote cartilage repair. In this line of work, Zhang et al. [113] performed a study in which a magnetic scaffold was fabricated by mixing a hybrid hydrogel composed of $\mathrm{HA}$, type II collagen and PEG with PVA modified $\mathrm{Fe}_{3} \mathrm{O}_{4}$ magnetic particles by mechanical dispersion. The magnetic hydrogel showed the ability to support BMSC behaviour in vitro, although the effect of magnetic stimulation of the hydrogel on the cells was not evaluated. However, not only it is necessary to maintain bone marrow stem cell (BMSC) behaviour in vitro, but the need to promote chondrogenic differentiation poses a new challenge. This process requires the addition of cytokines, but the currently available cytokines have a short half-life. Yang et al. [211] developed a cellulose nanocrystal/dextran hydrogel with MNPs. These MNPs were grafted with kartogenin (KGN), an important cytokine, which allowed for a controlled and long-term sustained release of the cytokine. This controlled release of KGN improved host cell recruitment and induced BMSC differentiation, improving in situ cartilage regeneration. However, a long-term exposure to magnetic fields may entail negative effects on osteogenic cell differentiation [201,212]. These principles can be extended to cartilage that, due to the lack of endogenous restoration of cartilage tissue within bone joints after damage, needs further development by means of tissue engineering [189]. However, more studies are needed to explore the influence of the magnetically induced mechanical forces on the behaviour of magneto-active scaffolds [213]. 


\subsection{MAPs for Drug Delivery}

A biomedical field with great potential for MAPs is drug delivery. Conventional drug delivery lacks tissue specificity and one of its major drawbacks is to surpass natural physiological barriers [192]. The use of MAPs encapsulating the drug open the window to deliver specific therapeutic agents in situ to a specific target site. These MAPs consist of injectable nanoengineered hydrogels loaded with magnetic particles for localised, on demand delivery of therapeutics. To this end, an external magnetic field can be applied to direct the MAP carrying the drug to the desired region. Once there, the MAP allows for spatiotemporal modifications by applying an external magnetic field that tunes the drug release and concentration depending on metabolic changes with a minimal invasive surgery $[189,214]$. These hydrogels must be shear-thinning and self-recoverable modulating the cross-linking degree [215]. Another advantage of these systems is that they prevent hitting the drug concentration peak which is metabolically undesirable. Instead, these MAPs allow for controlled drug delivery systems that are capable of keeping a constant drug concentration for longer, which is beneficial for the treatment of illnesses that follow a rhythmic pattern such as diabetes $[189,216-218]$. Thus, these systems can be applied to release drugs for extended periods of time in illnesses that follow a rhythmic pattern, such as diabetes, depression, hypertension, arthritis or asthma [219,220].

In this field in particular, magnetic nanoparticles are extremely attractive for controlling drug delivery because their properties and behaviour can be easily modified by a magnetic field, which can be applied externally [221]. However, the main drawbacks of MNPs for drug delivery are the small amounts of drugs that can be linked to each NP, the possibility of drug deactivation once it is chemically bound to the NP, and the possibility of its immediate uncontrollable passive release (burst effect) [222]. These drawbacks can be addressed by introducing these magnetic particles into a hydrogel. [110] developed and characterised magnetic hydrogels by chemically cross-linking gelatine hydrogels and $\mathrm{Fe}_{3} \mathrm{O}_{4}$ nanoparticles and loading with vitamin B12. By the application of an alternating magnetic field, both the swelling rate and the drug release rate were modified. While the magnetic field was turned on, the swelling rate decreased rapidly, even reaching "deswealing" rates, while the release rate was increased during the "on" times. The authors of [223] developed a novel hybrid magnetic hydrogel with CoFE2O4 nanoparticles as cross-linker agents for carboxymethylcellulose (CMC) polymer as a smart drug delivery system. Using MNPs as the crosslinking agent, the drawback of possible release of MNPs from the hydrogel to the external environment through diffusion was overcome. [224] developed B-cyclodextrin/cellulose hydrogel beads for drug delivery, which exhibited rapid swelling-deswelling properties under an external magnetic field (EMF) to remotely control drug release. The efficiency of the hydrogel in the stepwise drug release dose and rate can be controlled by switching on-off the EMF and by adjusting the MNPs concentration. An interesting approach to magnetic-based smart drug delivery is the development of hybrid thermoresponsive magnetic hydrogels. This approach combines both thermoresponsive hydrogels, such as poly(N-isopropylacrylamide) (PNIPAM) with magnetic nanoparticles. MNPs have been shown to generate heat under application of an alternating magnetic field (AMF). The heat produced by the relaxation mechanisms of magnetic nanoparticles influences the swelling and de-swelling behaviour of the thermoresponsive hydrogel, which allows for the controlled release of the encapsulated drug [225].

\subsection{MAPs for Tissue Hyperthermia}

Another potential use of MAPs relies on their ability to introduce located heating, with great potential in cancer therapy. Chemotherapy is well known to present severe problems such as drug resistance and to be very toxic for the patient. Apart from the advantages that MAPs can provide for delivering drug at a specific site, these nanomaterials can also be used for hyperthermia treatment. Hyperthermia is an interesting approach for cancer treatment, since it has been proven that temperatures between 40 and $44^{\circ} \mathrm{C}$ have been proven cytotoxic for cells in an environment with a low $p=2$ and $\mathrm{pH}$, 
conditions found specifically within tumour tissue due to insufficient blood perfusion. Under these conditions, radiotherapy is less effective, and systemically applied cytotoxic agents will reach cancer tissue in lower concentrations than well perfused areas, so hyperthermia shows itself as promising approach to target tumours [226]. For that, magneto-active nanoparticles can be employed to release energy under high frequency magnetic fields, thus killing malignant cells or release chemotherapeutics at the tumour site [188,191,194-197]. This increase in temperature is achieved by subjecting the magnetic hydrogels to an alternating magnetic field, reaching temperatures as high as $45^{\circ} \mathrm{C}$. Many materials have been tested for this purpose, such as Poly ( $\mathrm{N}$-isopropylacrylamide) (PNIPA) [227], Poly(ethylene glycol) [228] or even double-network hydrogels composed by alginate and PNIPA [133], all of them including soft-magnetic iron oxide particles.

\subsection{MAPs for Artificial Muscles}

Moreover, MAPs have motivated a new generation of artificial muscles and soft actuators. A few studies have begun to examine the application of MAHs as soft actuators for biomedical applications due to their ability to be controlled remotely [189]. A promising application of this proposes the development of artificial muscles able to reproduce complex and large muscle actuation in the body: bending, deformation, motion or contraction [229]. Finally, MAPs have valuable applications due to their magnetic properties, low background noise, highly biocompatibility and good dispersion, that can be leveraged in the development of biosensing and monitoring devices. They can be classified into optical (colorimetric, fluorescent, surface plasmon resonance, surface-enhanced Ramman scattering) or electrochemical (potentiometric, conductometric, amperometric, impedimetric) and can be used for the identification of biological targets in high-throughput purposes achieving highly sensitive and sensing performance [230,231].

\subsection{MAPs for Neuronal Regeneration}

When developing engineered tissue in vitro, one of the major challenges and requirements is the integration of its vascularisation to provide correct viability and promote growth when implanted in vivo [189]. To overcome these issues, micro-ring scaffolds with magnetic alginate microfibers offer a timely solution, promoting microvascular-like structures [232]. These problems are also present in neuronal regeneration. In recent years, motivated by the lack of natural repair of the central nervous system (reducing life quality of the patients), the development of magneto-responsive biomaterials is being investigated to promote neuronal regeneration $[189,192]$. These systems have demonstrated an improvement in neuronal network formation, growth and organisation when subjecting magnetic microbead scaffolds to a controlled magnetic field [233].

\section{Conclusions}

Mechanics fundamentals, although sometimes disregarded, are the driving force of several biological processes and are present in almost all of them at some instance. Throughout this manuscript, important examples have been reviewed, such as mechanoelectrophysiological couplings in neuronal or brain response, bone healing processes, or cell proliferation and migration. These mechanical dependences open the question on if we may be able to control biological processes by modulating the mechanical environment in which they take place. To be suitable, such a modulation should be remote and reversible. In this regard, novel multifunctional materials that mechanically respond to magnetic stimuli, i.e., magneto-active polymers (MAPs), are ideal candidates. However, despite the great potential of MAPs for biomedical applications, there are still some limitations that prevent their exploitation.

Due to the nature of the components of magneto-responsive particles, their biological behaviour differs from single polymer scaffolds. The influence of the magnetic particles on these new materials suggest that they are potentially benign and useful in most of the abovementioned biomedical applications [200,234,235]. Despite these encouraging 
results, there are still more studies to be conducted to assess possible toxicity or side effects [236-238]. Another important aspect to take into consideration when developing a magnetic biomaterial for biomedical purposes is their antibacterial properties regarding the particle size, density and composition [201,239-241]. Although biocompatibility and antibacterial properties of magneto-responsive hydrogels have been widely studied, their metabolism, distribution and long-term effect on tissues and organs have not been yet tested in vivo [242].

Moreover, from the modelling perspective, there is still a significant gap in the knowledge of fully coupled microstructural to macrostructural approaches in magneto-mechanics. In this regard, the overall response of the MAP does not depend only on the microstructural characteristics of the composite but also on structural responses arising from magnetic boundary conditions, fringing effects, presence of external magnetic poles, etc. In addition, the modelling of magneto-mechanical effects on biological processes is still an open question.

Author Contributions: All authors have contributed to the original writing of the article. All authors have read and agreed to the published version of the manuscript.

Funding: This work has been supported by the Madrid Government (Comunidad de Madrid) under the Multiannual Agreement with UC3M in the line of "Fostering Young Doctors Research" (BIOMASKIN-CM-UC3M), and in the context of the V PRICIT (Regional Programme of Research and Technological Innovation, and support from the European Research Council (ERC) under the European Union's Horizon 2020 research and innovation programme (grant agreement No. 947723). DGG acknowledges support from the Talent Attraction grant (CM 2018-2018-T2/IND-9992) from the Comunidad de Madrid.

Institutional Review Board Statement: Not applicable.

Informed Consent Statement: Not applicable.

Conflicts of Interest: The authors declare no conflict of interest.

\section{References}

1. Morrison, B.; Cater, H.L.; Benham, C.D.; Sundstrom, L.E. An in vitro model of traumatic brain injury utilising two-dimensional stretch of organotypic hippocampal slice cultures. J. Neurosci. Methods 2006, 150, 192-201. [CrossRef] [PubMed]

2. Garcia-Gonzalez, D.; Jerusalem, A. Energy based mechano-electrophysiological model of CNS damage at the tissue scale. J. Mech. Phys. Solids 2019, 125, 22-37. [CrossRef]

3. Brown, G.N.; Sattler, R.L.; Guo, X.E. Experimental studies of bone mechanoadaptation: Bridging in vitro and in vivo studies with multiscale systems. Interface Focus 2016, 6. [CrossRef] [PubMed]

4. Schmidt, I.; Papastavrou, A.; Steinmann, P. Concurrent consideration of cortical and cancellous bone within continuum bone remodelling. Comput. Methods Biomech. Biomed. Eng. 2021, 24, 1-12. [CrossRef]

5. Valencia, A.M.J.; Wu, P.-H.; Yogurtcu, O.; Rao, P.; Digiacomo, J.; Godet, I.; He, L.; Lee, M.-H.; Gilkes, D.; Sun, S.X.; et al. Collective cancer cell invasion induced by coordinated contractile stresses. Oncotarget 2015, 6, 43438-43451. [CrossRef] [PubMed]

6. Naveed, H.; Xu, L.X.; Li, Y.; Liang, J. Effects of mechanical properties on tumor invasion: Insights from a cellular model. In Proceedings of the 2014 36th Annual International Conference of the IEEE Engineering in Medicine and Biology Society, Chicago, IL, USA, 26-30 August 2014; IEEE: New York, NY, USA; pp. 6818-6821.

7. Sunyer, R.; Conte, V.; Escribano, J.; Elosegui-Artola, A.; Labernadie, A.; Valon, L.; Navajas, D.; García-Aznar, J.M.; Muñoz, J.J.; Roca-Cusachs, P.; et al. Collective cell durotaxis emerges from long-range intercellular force transmission. Science 2016, 353, 1157-1161. [CrossRef] [PubMed]

8. Garcia-Gonzalez, D.; Muñoz-Barrutia, A. Computational insights into the influence of substrate stiffness on collective cell migration. Extrem. Mech. Lett. 2020, 40, 100928. [CrossRef]

9. Budday, S.; Ovaert, T.C.; Holzapfel, G.A.; Steinmann, P.; Kuhl, E. Fifty Shades of Brain: A Review on the Mechanical Testing and Modeling of Brain Tissue. Arch. Comput. Methods Eng. 2019, 27, 1187-1230. [CrossRef]

10. Tyler, W.J. The mechanobiology of brain function. Nat. Rev. Neurosci. 2012, 13, 867-878. [CrossRef] [PubMed]

11. Calhoun, M.A.; Bentil, S.A.; Elliott, E.; Otero, J.J.; Winter, J.O.; Dupaix, R.B. Beyond Linear Elastic Modulus: Viscoelastic Models for Brain and Brain Mimetic Hydrogels. ACS Biomater. Sci. Eng. 2019, 5, 3964-3973. [CrossRef] [PubMed]

12. Lu, Y.-B.; Franze, K.; Seifert, G.; Steinhauser, C.; Kirchhoff, F.; Wolburg, H.; Guck, J.; Janmey, P.; Wei, E.-Q.; Kas, J.; et al. Viscoelastic properties of individual glial cells and neurons in the CNS. Proc. Natl. Acad. Sci. USA 2006, 103, 17759-17764. [CrossRef] [PubMed]

13. Anderson, D.K.; Hall, E.D. Pathophysiology of spinal cord trauma. Ann. Emerg. Med. 1993, 22, 987-992. [CrossRef] 
14. Maikos, J.T.; Qian, Z.; Metaxas, D.; Shreiber, D. Finite Element Analysis of Spinal Cord Injury in the Rat. J. Neurotrauma 2008, 25, 795-816. [CrossRef] [PubMed]

15. Warden, D. Military TBI during the Iraq and Afghanistan Wars. J. Head Trauma Rehabil. 2006, 21, 398-402. [CrossRef]

16. Jannesar, S.; Allen, M.; Mills, S.; Gibbons, A.; Bresnahan, J.C.; Salegio, E.A.; Sparrey, C.J. Compressive mechanical characterization of non-human primate spinal cord white matter. Acta Biomater. 2018, 74, 260-269. [CrossRef] [PubMed]

17. Wolter, A.; Rapp, A.E.; Durst, M.S.; Hildebrand, L.; Löhning, M.; Buttgereit, F.; Schmidt-Bleek, K.; Jirkof, P.; Lang, A. Systematic review on the reporting accuracy of experimental details in publications using mouse femoral fracture models. Bone 2021, 152, 116088. [CrossRef] [PubMed]

18. Jha, R.M.; Kochanek, P.M.; Simard, J.M. Pathophysiology and treatment of cerebral edema in traumatic brain injury. Neuropharmacology 2019, 145, 230-246. [CrossRef]

19. Simpson, D.M.; Payne, S.J.; Panerai, R.B. The INfoMATAS project: Methods for assessing cerebral autoregulation in stroke. Br. J. Pharmacol. 2021. [CrossRef]

20. Bing, Y.; Garcia-Gonzalez, D.; Voets, N.; Jérusalem, A. Medical imaging based in silico head model for ischaemic stroke simulation. J. Mech. Behav. Biomed. Mater. 2019, 101, 103442. [CrossRef]

21. McDermott, A.M.; Herberg, S.; Mason, D.E.; Collins, J.M.; Pearson, H.B.; Dawahare, J.H.; Tang, R.; Patwa, A.N.; Grinstaff, M.W.; Kelly, D.J.; et al. Recapitulating bone development through engineered mesenchymal condensations and mechanical cues for tissue regeneration. Sci. Transl. Med. 2019, 11, eaav7756. [CrossRef] [PubMed]

22. Rosa, N.; Simoes, R.; Magalhães, F.D.; Marques, A.T. From mechanical stimulus to bone formation: A review. Med. Eng. Phys. 2015, 37, 719-728. [CrossRef]

23. Stock, J.T. Wolff's law (bone functional adaptation). In The International Encyclopedia of Biological Anthropology; Wiley: Hoboken, NJ, USA, 2018; pp. 1-2. [CrossRef]

24. Papastavrou, A.; Schmidt, I.; Steinmann, P. On biological availability dependent bone remodeling. Comput. Methods Biomech. Biomed. Eng. 2020, 23, 432-444. [CrossRef] [PubMed]

25. Kummer, B. Basics of Pauwels' theory of the functional adaptation of bones. Der Orthopäde 1995, 24, 387-393. [PubMed]

26. Claes, L.; Heigele, C. Magnitudes of local stress and strain along bony surfaces predict the course and type of fracture healing. $J$. Biomech. 1999, 32, 255-266. [CrossRef]

27. Handorf, A.M.; Zhou, Y.; Halanski, M.A.; Li, W.-J. Tissue Stiffness Dictates Development, Homeostasis, and Disease Progression. Organogenesis 2015, 11, 1-15. [CrossRef] [PubMed]

28. Schell, H.; Duda, G.N.; Peters, A.; Tsitsilonis, S.; Johnson, K.A.; Schmidt-Bleek, K. The haematoma and its role in bone healing. J. Exp. Orthop. 2017, 4, 1-11. [CrossRef] [PubMed]

29. Einhorn, T.A.; Gerstenfeld, L.C. Fracture healing: Mechanisms and interventions. Nat. Rev. Rheumatol. 2015, 11, 45-54. [CrossRef]

30. Nyary, T.; Scammell, B.E. Principles of bone and joint injuries and their healing. Surgery 2018, 36, 7-14. [CrossRef]

31. Strube, P.; Sentuerk, U.; Riha, T.; Kaspar, K.; Mueller, M.; Kasper, G.; Matziolis, G.; Duda, G.N.; Perka, C. Influence of age and mechanical stability on bone defect healing: Age reverses mechanical effects. Bone 2008, 42, 758-764. [CrossRef] [PubMed]

32. Frohlich, M.; Grayson, W.; Wan, L.; Marolt, D.; Drobnic, M.; Novakovic, G.V. Tissue Engineered Bone Grafts: Biological Requirements, Tissue Culture and Clinical Relevance. Curr. Stem Cell Res. Ther. 2008, 3, 254-264. [CrossRef]

33. Carroll, S.F.; Buckley, C.; Kelly, D.J. Cyclic Tensile Strain Can Play a Role in Directing both Intramembranous and Endochondral Ossification of Mesenchymal Stem Cells. Front. Bioeng. Biotechnol. 2017, 5, 73. [CrossRef]

34. Hadjidakis, D.J.; Androulakis, I.I. Bone Remodeling. Ann. Acad. Sci. 2006, 1092, 385-396. [CrossRef] [PubMed]

35. Thomas, J.D.; Kehoe, J.L. Bone Nonunion; StatPearls Publishing: Treasure Island, FL, USA, 2021.

36. Ghiasi, M.S.; Chen, J.; Vaziri, A.; Rodriguez, E.K.; Nazarian, A. Bone fracture healing in mechanobiological modeling: A review of principles and methods. Bone Rep. 2017, 6, 87-100. [CrossRef]

37. García-Aznar, J.M.; Nasello, G.; Hervas-Raluy, S.; Pérez, M.Á.; Gómez-Benito, M.J. Multiscale modeling of bone tissue mechanobiology. Bone 2021, 151, 116032. [CrossRef] [PubMed]

38. Ghiasi, M.S.; Chen, J.E.; Rodriguez, E.K.; Vaziri, A.; Nazarian, A. Computational modeling of human bone fracture healing affected by different conditions of initial healing stage. BMC Musculoskelet. Disord. 2019, 20, 562-614. [CrossRef] [PubMed]

39. Borgiani, E.; Duda, G.N.; Checa, S. Multiscale Modeling of Bone Healing: Toward a Systems Biology Approach. Front. Physiol. 2017, 8, 287. [CrossRef] [PubMed]

40. Friedl, P.; Gilmour, D. Collective cell migration in morphogenesis, regeneration and cancer. Nat. Rev. Mol. Cell Biol. 2009, 10, 445-457. [CrossRef]

41. Schwarz, U.S.; Ziebert, F. When tissues collide. Nat. Mater. 2017, 16, 972-973. [CrossRef]

42. Barriga, E.H.; Franze, K.; Charras, G.; Mayor, R. Tissue stiffening coordinates morphogenesis by triggering collective cell migration in vivo. Nat. Cell Biol. 2018, 554, 523-527. [CrossRef]

43. Anon, E.; Serra-Picamal, X.; Hersen, P.; Gauthier, N.C.; Sheetz, M.P.; Trepat, X.; Ladoux, B. Cell crawling mediates collective cell migration to close undamaged epithelial gaps. Proc. Natl. Acad. Sci. USA 2012, 109, 10891-10896. [CrossRef]

44. Barnes, L.A.; Marshall, C.D.; Leavitt, T.; Hu, M.S.; Moore, A.L.; Gonzalez, J.G.; Longaker, M.T.; Gurtner, G.C. Mechanical Forces in Cutaneous Wound Healing: Emerging Therapies to Minimize Scar Formation. Adv. Wound Care 2018, 7, 47-56. [CrossRef] [PubMed] 
45. Malandrino, A.; Mak, M.; Kamm, R.D.; Moeendarbary, E. Complex mechanics of the heterogeneous extracellular matrix in cancer. Extreme Mech. Lett. 2018, 21, 25-34. [CrossRef]

46. Lo, C.-M.; Wang, H.-B.; Dembo, M.; Wang, Y.-L. Cell Movement Is Guided by the Rigidity of the Substrate. Biophys. J. 2000, 79, 144-152. [CrossRef]

47. Küsters, B.; Kats, G.; Roodink, I.; Verrijp, K.; Wesseling, P.; Ruiter, D.J.; De Waal, R.M.W.; Leenders, W. Micronodular transformation as a novel mechanism of VEGF-A-induced metastasis. Oncogene 2007, 26, 5808-5815. [CrossRef]

48. Soler-Cardona, A.; Forsthuber, A.; Lipp, K.; Ebersberger, S.; Heinz, M.; Schossleitner, K.; Buchberger, E.; Gröger, M.; Petzelbauer, P.; Hoeller, C.; et al. CXCL5 Facilitates Melanoma Cell-Neutrophil Interaction and Lymph Node Metastasis. J. Investig. Dermatol. 2018, 138, 1627-1635. [CrossRef] [PubMed]

49. Paul, C.D.; Mistriotis, P.; Konstantopoulos, K. Cancer cell motility: Lessons from migration in confined spaces. Nat. Rev. Cancer 2017, 17, 131-140. [CrossRef]

50. Liu, Y.-J.; Le Berre, M.; Lautenschläger, F.; Maiuri, P.; Callan-Jones, A.; Heuze, M.; Takaki, T.; Voituriez, R.; Piel, M. Confinement and Low Adhesion Induce Fast Amoeboid Migration of Slow Mesenchymal Cells. Cell 2015, 160, 659-672. [CrossRef] [PubMed]

51. Wisniewski, E.O.; Mistriotis, P.; Bera, K.; Law, R.A.; Zhang, J.; Nikolic, M.; Weiger, M.; Parlani, M.; Tuntithavornwat, S.; Afthinos, A.; et al. Dorsoventral polarity directs cell responses to migration track geometries. Sci. Adv. 2020, 6, eaba6505. [CrossRef] [PubMed]

52. Karimi, A.; Shojaei, A.; Tehrani, P. Mechanical properties of the human spinal cord under the compressive loading. J. Chem. Neuroanat. 2017, 86, 15-18. [CrossRef]

53. Kleiven, S.; Hardy, W.N. Correlation of an FE Model of the Human Head with Local Brain Motion-Consequences for Injury Prediction. Stapp Car Crash J. 2002, 46, 123-144. [CrossRef] [PubMed]

54. Alvarez, V.S.; Kleiven, S. Effect of pediatric growth on cervical spine kinematics and deformations in automotive crashes. J. Biomech. 2018, 71, 76-83. [CrossRef]

55. Giordano, C.; Zappalà, S.; Kleiven, S. Anisotropic finite element models for brain injury prediction: The sensitivity of axonal strain to white matter tract inter-subject variability. Biomech. Model. Mechanobiol. 2017, 16, 1269-1293. [CrossRef] [PubMed]

56. Wright, R.M.; Post, A.; Hoshizaki, B.; Ramesh, K.T. A Multiscale Computational Approach to Estimating Axonal Damage under Inertial Loading of the Head. J. Neurotrauma 2013, 30, 102-118. [CrossRef]

57. Garcia-Gonzalez, D.; Race, N.; Voets, N.L.; Jenkins, D.R.; Sotiropoulos, S.; Acosta, G.; Cruz-Haces, M.; Tang, J.; Shi, R.; Jérusalem, A. Cognition based bTBI mechanistic criteria; a tool for preventive and therapeutic innovations. Sci. Rep. 2018, 8, 1-14. [CrossRef]

58. Boucher, P.-A.; Joós, B.; Morris, C.E. Coupled left-shift of Nav channels: Modeling the Na+-loading and dysfunctional excitability of damaged axons. J. Comput. Neurosci. 2012, 33, 301-319. [CrossRef] [PubMed]

59. Babbs, C.F.; Shi, R. Subtle Paranodal Injury Slows Impulse Conduction in a Mathematical Model of Myelinated Axons. PLoS ONE 2013, 8, e67767. [CrossRef] [PubMed]

60. Jérusalem, A.; García-Grajales, J.A.; Merchan-Perez, A.; Peña, J.M. A computational model coupling mechanics and electrophysiology in spinal cord injury. Biomech. Model. Mechanobiol. 2014, 13, 883-896. [CrossRef]

61. García-Grajales, J.A.; Rucabado, G.; García-Dopico, A.; Peña, J.-M.; Jerusalem, A. Neurite, a Finite Difference Large Scale Parallel Program for the Simulation of Electrical Signal Propagation in Neurites under Mechanical Loading. PLoS ONE 2015, 10, e0116532. [CrossRef] [PubMed]

62. Kwong, M.T.; Bianchi, F.; Malboubi, M.; García-Grajales, J.A.; Homsi, L.; Thompson, M.; Ye, H.; Noels, L.; Jérusalem, A. 3D finite element formulation for mechanical-electrophysiological coupling in axonopathy. Comput. Methods Appl. Mech. Eng. 2018, 346, 1025-1050. [CrossRef]

63. Cinelli, I.; Destrade, M.; McHugh, P.; Duffy, M. Effects of nerve bundle geometry on neurotrauma evaluation. Int. J. Numer. Methods Biomed. Eng. 2018, 34, e3118. [CrossRef] [PubMed]

64. Cinelli, I.; Destrade, M.; Duffy, M.; McHugh, P. Electrothermal Equivalent Three-Dimensional Finite-Element Model of a Single Neuron. IEEE Trans. Biomed. Eng. 2017, 65, 1373-1381. [CrossRef]

65. Cinelli, I.; Destrade, M.; Duffy, M.; McHugh, P. Electro-mechanical response of a 3D nerve bundle model to mechanical loads leading to axonal injury. Int. J. Numer. Methods Biomed. Eng. 2018, 34, e2942. [CrossRef] [PubMed]

66. El Hady, A.; Machta, B.B. Mechanical surface waves accompany action potential propagation. Nat. Commun. 2015, 6, 6697. [CrossRef] [PubMed]

67. Engelbrecht, J.; Tamm, K.; Peets, T. Internal variables used for describing the signal propagation in axons. Contin. Mech. Thermodyn. 2020, 32, 1619-1627. [CrossRef]

68. Peets, T.; Tamm, K.; Engelbrecht, J. On the Physical Background of Nerve Pulse Propagation: Heat and Energy. J. Non-Equilib. Thermodyn. 2021, 46. [CrossRef]

69. Engelbrecht, J.; Tamm, K.; Peets, T. Modelling of processes in nerve fibres at the interface of physiology and mathematics. Biomech. Model. Mechanobiol. 2020, 19, 2491-2498. [CrossRef] [PubMed]

70. Chen, H.; Garcia-Gonzalez, D.; Jérusalem, A. Computational model of the mechanoelectrophysiological coupling in axons with application to neuromodulation. Phys. Rev. E 2019, 99, 032406. [CrossRef] [PubMed]

71. Jerusalem, A.; Al-Rekabi, Z.; Chen, H.; Ercole, A.; Malboubi, M.; Tamayo-Elizalde, M.; Verhagen, L.; Contera, S. Electrophysiological-mechanical coupling in the neuronal membrane and its role in ultrasound neuromodulation and general anaesthesia. Acta Biomater. 2019, 97, 116-140. [CrossRef] [PubMed] 
72. Chan, B.P.; Leong, K.W. Scaffolding in tissue engineering: General approaches and tissue-specific considerations. Eur. Spine, J. 2008, 17, 467-479. [CrossRef] [PubMed]

73. Basson, M.A. Signaling in Cell Differentiation and Morphogenesis. Cold Spring Harb. Perspect. Biol. 2012, 4, a008151. [CrossRef]

74. Geris, L.; Gerisch, A.; Sloten, J.V.; Weiner, R.; Van Oosterwyck, H. Angiogenesis in bone fracture healing: A bioregulatory model. J. Theor. Biol. 2008, 251, 137-158. [CrossRef]

75. Bailón-Plaza, A.; van der Meulen, M.C.H. A Mathematical Framework to Study the Effects of Growth Factor Influences on Fracture Healing. J. Theor. Biol. 2001, 212, 191-209. [CrossRef]

76. Buenzli, P.R.; Pivonka, P.; Gardiner, B.; Smith, D.W. Modelling the anabolic response of bone using a cell population model. J. Theor. Biol. 2012, 307, 42-52. [CrossRef]

77. Carlier, A.; van Gastel, N.; Geris, L.; Carmeliet, G.; Van Oosterwyck, H. Size Does Matter: An Integrative In Vivo-In Silico Approach for the Treatment of Critical Size Bone Defects. PLoS Comput. Biol. 2014, 10, e1003888. [CrossRef]

78. Carlier, A.; Geris, L.; Bentley, K.; Carmeliet, G.; Carmeliet, P.; Van Oosterwyck, H. MOSAIC: A Multiscale Model of Osteogenesis and Sprouting Angiogenesis with Lateral Inhibition of Endothelial Cells. PLoS Comput. Biol. 2012, 8, e1002724. [CrossRef] [PubMed]

79. Lacroix, D.; Prendergast, P. A mechano-regulation model for tissue differentiation during fracture healing: Analysis of gap size and loading. J. Biomech. 2002, 35, 1163-1171. [CrossRef]

80. Lacroix, D.; Prendergast, P.J.; Li, G.; Marsh, D. Biomechanical model to simulate tissue differentiation and bone regeneration: Application to fracture healing. Med. Biol. Eng. Comput. 2002, 40, 14-21. [CrossRef]

81. Checa, S.; Prendergast, P.J. A Mechanobiological Model for Tissue Differentiation that Includes Angiogenesis: A Lattice-Based Modeling Approach. Ann. Biomed. Eng. 2009, 37, 129-145. [CrossRef] [PubMed]

82. Wilson, C.J.; Schuetz, M.A.; Epari, D.R. Effects of strain artefacts arising from a pre-defined callus domain in models of bone healing mechanobiology. Biomech. Model. Mechanobiol. 2015, 14, 1129-1141. [CrossRef] [PubMed]

83. Prendergast, P.; Huiskes, R.; Søballe, K. Biophysical stimuli on cells during tissue differentiation at implant interfaces. J. Biomech. 1997, 30, 539-548. [CrossRef]

84. Ribeiro, F.O.; Gómez-Benito, M.J.; Folgado, J.; Fernandes, P.R.; García-Aznar, J.M. In silico Mechano-Chemical Model of Bone Healing for the Regeneration of Critical Defects: The Effect of BMP. PLoS ONE 2015, 10, e0127722. [CrossRef]

85. Isaksson, H.; Wilson, W.; van Donkelaar, C.C.; Huiskes, R.; Ito, K. Comparison of biophysical stimuli for mechano-regulation of tissue differentiation during fracture healing. J. Biomech. 2006, 39, 1507-1516. [CrossRef] [PubMed]

86. Alierta, J.A.; Pérez, M.A.; García-Aznar, J.M. An interface finite element model can be used to predict healing outcome of bone fractures. J. Mech. Behav. Biomed. Mater. 2014, 29, 328-338. [CrossRef]

87. Comellas, E.; Gasser, T.C.; Bellomo, F.J.; Oller, S. A homeostatic-driven turnover remodelling constitutive model for healing in soft tissues. J. R. Soc. Interface 2016, 13, 20151081. [CrossRef]

88. Alert, R.; Trepat, X. Physical Models of Collective Cell Migration. Annu. Rev. Condens. Matter Phys. 2020, 11, 77-101. [CrossRef]

89. Köpf, M.H.; Pismen, L.M. A continuum model of epithelial spreading. Soft Matter 2013, 9, 3727-3734. [CrossRef]

90. Alert, R.; Blanch-Mercader, C.; Casademunt, J. Active Fingering Instability in Tissue Spreading. Phys. Rev. Lett. 2019, 122, 088104. [CrossRef]

91. Notbohm, J.; Banerjee, S.; Utuje, K.J.; Gweon, B.; Jang, H.; Park, Y.; Shin, J.; Butler, J.P.; Fredberg, J.J.; Marchetti, M.C. Cellular Contraction and Polarization Drive Collective Cellular Motion. Biophys. J. 2016, 110, 2729-2738. [CrossRef]

92. Metzcar, J.; Wang, Y.; Heiland, R.; Macklin, P. A Review of Cell-Based Computational Modeling in Cancer Biology. JCO Clin. Cancer Inform. 2019, 3, 1-13. [CrossRef] [PubMed]

93. Weerasinghe, H.N.; Burrage, P.M.; Burrage, K.; Nicolau, D.V. Mathematical Models of Cancer Cell Plasticity. J. Oncol. 2019, 2019, 2403483. [CrossRef] [PubMed]

94. Aguilar, M.R.; Román, J.S. Introduction to smart polymers and their applications. In Smart Polymers and their Applications, 2nd edition; Woodhead Publishing: Cambridge, UK, 2014; pp. 1-11. [CrossRef]

95. Khan, F.; Tanaka, M. Designing Smart Biomaterials for Tissue Engineering. Int. J. Mol. Sci. 2017, 19, 17. [CrossRef] [PubMed]

96. Kowalski, P.S.; Bhattacharya, C.; Afewerki, S.; Langer, R.S. Smart Biomaterials: Recent Advances and Future Directions. ACS Biomater. Sci. Eng. 2018, 4, 3809-3817. [CrossRef]

97. Fenton, O.S.; Olafson, K.N.; Pillai, P.S.; Mitchell, M.; Langer, R. Advances in Biomaterials for Drug Delivery. Adv. Mater. 2018, 30, e1705328. [CrossRef] [PubMed]

98. Holzapfel, B.M.; Reichert, J.C.; Schantz, J.-T.; Gbureck, U.; Rackwitz, L.; Nöth, U.; Jakob, F.; Rudert, M.; Groll, J.; Hutmacher, D.W. How smart do biomaterials need to be? A translational science and clinical point of view. Adv. Drug Deliv. Rev. 2013, 65, 581-603. [CrossRef] [PubMed]

99. Vihola, H.; Laukkanen, A.; Valtola, L.; Tenhu, H.; Hirvonen, J.T. Cytotoxicity of thermosensitive polymers poly(Nisopropylacrylamide), poly(N-vinylcaprolactam) and amphiphilically modified poly(N-vinylcaprolactam). Biomaterials 2005, 26, 3055-3064. [CrossRef]

100. Vihola, H.; Marttila, A.; Pakkanen, J.; Andersson, M.; Laukkanen, A.; Kaukonen, A.; Tenhu, H.; Hirvonen, J. Cell-polymer interactions of fluorescent polystyrene latex particles coated with thermosensitive poly(N-isopropylacrylamide) and poly(Nvinylcaprolactam) or grafted with poly(ethylene oxide)-macromonomer. Int. J. Pharm. 2007, 343, 238-246. [CrossRef] 
101. Kim, M.S.; Hyun, H.; Seo, K.S.; Cho, Y.H.; Lee, J.W.; Lee, C.R.; Khang, G.; Lee, H.B. Preparation and characterization of MPEG-PCL diblock copolymers with thermo-responsive sol-gel-sol phase transition. J. Polym. Sci. Part. A Polym. Chem. 2006, 44, 5413-5423. [CrossRef]

102. Yoon, J.A.; Gayathri, C.; Gil, R.R.; Kowalewski, T.; Matyjaszewski, K. Comparison of the Thermoresponsive Deswelling Kinetics of Poly(2-(2-methoxyethoxy)ethyl methacrylate) Hydrogels Prepared by ATRP and FRP. Macromolecules 2010, 43, $4791-4797$. [CrossRef]

103. Hu, Z.; Cai, T.; Chi, C. Thermoresponsive oligo(ethylene glycol)-methacrylate- based polymers and microgels. Soft Matter 2010, 6 , 2115-2123. [CrossRef]

104. Becer, R.; Hahn, S.; Fijten, M.W.M.; Thijs, H.M.L.; Hoogenboom, R.; Schubert, U. Libraries of methacrylic acid and oligo(ethylene glycol) methacrylate copolymers with LCST behavior. J. Polym. Sci. Part. A Polym. Chem. 2008, 46, 7138-7147. [CrossRef]

105. Shimizu, K.; Fujita, H.; Nagamori, E. Oxygen plasma-treated thermoresponsive polymer surfaces for cell sheet engineering. Biotechnol. Bioeng. 2010, 106, 303-310. [CrossRef] [PubMed]

106. Stile, R.A.; Healy, K.E. Thermo-Responsive Peptide-Modified Hydrogels for Tissue Regeneration. Biomacromolecules 2001, 2, 185-194. [CrossRef]

107. Bertrand, O.; Gohy, J.-F. Photo-responsive polymers: Synthesis and applications. Polym. Chem. 2016, 8, 52-73. [CrossRef]

108. Manouras, T.; Vamvakaki, M. Field responsive materials: Photo-, electro-, magnetic- and ultrasound-sensitive polymers. Polym. Chem. 2017, 8, 74-96. [CrossRef]

109. Chang, L.; Liu, Y.; Yang, Q.; Yu, L.; Liu, J.; Zhu, Z.; Lu, P.; Wu, Y.; Hu, Y. Ionic Electroactive Polymers Used in Bionic Robots: A Review. J. Bionic Eng. 2018, 15, 765-782. [CrossRef]

110. Liu, T.-Y.; Hu, S.-H.; Liu, K.-H.; Liu, D.-M.; Chen, S.-Y. Preparation and characterization of smart magnetic hydrogels and its use for drug release. J. Magn. Magn. Mater. 2006, 304, e397-e399. [CrossRef]

111. Zrínyi, M.; Barsi, L.; Büki, A. Ferrogel: A new magneto-controlled elastic medium. Polym. Gels Netw. 1997, 5, 415-427. [CrossRef]

112. Barbucci, R.; Pasqui, D.; Giani, G.; De Cagna, M.; Fini, M.; Giardino, R.; Atrei, A. A novel strategy for engineering hydrogels with ferromagnetic nanoparticles as crosslinkers of the polymer chains. Potential applications as a targeted drug delivery system. Soft Matter 2011, 7, 5558-5565. [CrossRef]

113. Zhang, N.; Lock, J.; Sallee, A.; Liu, H. Magnetic Nanocomposite Hydrogel for Potential Cartilage Tissue Engineering: Synthesis, Characterization, and Cytocompatibility with Bone Marrow Derived Mesenchymal Stem Cells. ACS Appl. Mater. Interfaces 2015, 7, 20987-20998. [CrossRef] [PubMed]

114. Lee, C.J.; Kwon, S.H.; Choi, H.J.; Chung, K.H.; Jung, J.H. Enhanced magnetorheological performance of carbonyl iron/natural rubber composite elastomer with gamma-ferrite additive. Colloid Polym. Sci. 2018, 296, 1609-1613. [CrossRef]

115. Bidan, C.; Fratzl, M.; Coullomb, A.; Moreau, P.; Lombard, A.H.; Wang, I.; Balland, M.; Boudou, T.; Dempsey, N.M.; Devillers, T.; et al. Magneto-active substrates for local mechanical stimulation of living cells. Sci. Rep. 2018, 8, 1-13. [CrossRef] [PubMed]

116. Reyes-Ortega, F. 3-pH-responsive polymers: Properties, synthesis and applications. In Smart Polymers and their Applications; Aguilar, M.R., Román, J.S., Eds.; Woodhead Publishing: Cambridge, UK, 2014; pp. 45-92. [CrossRef]

117. Zhang, J.; Jiang, X.; Wen, X.; Xu, Q.; Zeng, H.; Zhao, Y.; Liu, M.; Wang, Z.; Hu, X.; Wang, Y. Bio-responsive smart polymers and biomedical applications. J. Phys. Mater. 2019, 2, 032004. [CrossRef]

118. Zrinyi, M. 5 -Magnetically responsive polymer gels and elastomers: Properties, synthesis and applications. In Smart Polymers and their Applications; Woodhead Publishing: Cambridge, UK, 2014; pp. 134-165. [CrossRef]

119. Moreno, M.; Gonzalez-Rico, J.; Lopez-Donaire, M.; Arias, A.; Garcia-Gonzalez, D. New experimental insights into magnetomechanical rate dependences of magnetorheological elastomers. Compos. Part. B Eng. 2021, 224, 109148. [CrossRef]

120. Han, Y.; Mohla, A.; Huang, X.; Hong, W.; Faidley, L.E. Magnetostriction and Field Stiffening of Magneto-Active Elastomers. Int. J. Appl. Mech. 2015, 7, 1550001. [CrossRef]

121. Bastola, A.K.; Hossain, M. A review on magneto-mechanical characterizations of magnetorheological elastomers. Compos. Part. B: Eng. 2020, 200, 108348. [CrossRef]

122. Bastola, A.K.; Paudel, M.; Li, L.; Li, W. Recent progress of magnetorheological elastomers: A review. Smart Mater. Struct. 2020, 29, 123002. [CrossRef]

123. Winger, J.; Schümann, M.; Kupka, A.; Odenbach, S. Influence of the particle size on the magnetorheological effect of magnetorheological elastomers. J. Magn. Magn. Mater. 2019, 481, 176-182. [CrossRef]

124. Zhao, R.; Kim, Y.; Chester, S.A.; Sharma, P.; Zhao, X. Mechanics of hard-magnetic soft materials. J. Mech. Phys. Solids 2019, 124, 244-263. [CrossRef]

125. Kim, Y.; Yuk, H.; Zhao, R.; Chester, S.A.; Zhao, X. Printing ferromagnetic domains for untethered fast-transforming soft materials. Nat. Cell Biol. 2018, 558, 274-279. [CrossRef]

126. Liu, X.; Liu, J.; Lin, S.; Zhao, X. Hydrogel machines. Mater. Today 2020, 36, 102-124. [CrossRef]

127. Goffin, J.M.; Pittet, P.; Csucs, G.; Lussi, J.W.; Meister, J.-J.; Hinz, B. Focal adhesion size controls tension-dependent recruitment of $\alpha$-smooth muscle actin to stress fibers. J. Cell Biol. 2006, 172, 259-268. [CrossRef] [PubMed]

128. Sunyer, R.; Jin, A.; Nossal, R.; Sackett, D.L. Fabrication of Hydrogels with Steep Stiffness Gradients for Studying Cell Mechanical Response. PLoS ONE 2012, 7, e46107. [CrossRef] [PubMed]

129. Yamada, N.; Okano, T.; Sakai, H.; Karikusa, F.; Sawasaki, Y.; Sakurai, Y. Thermo-responsive polymeric surfaces; control of attachment and detachment of cultured cells. Die Makromol. Chemie Rapid Commun. 1990, 11, 571-576. [CrossRef] 
130. Chan, E.W.L.; Park, S.; Yousaf, M.N. An Electroactive Catalytic Dynamic Substrate that Immobilizes and Releases Patterned Ligands, Proteins, and Cells. Angew. Chem. Int. Ed. 2008, 47, 6267-6271. [CrossRef]

131. Mayer, M.; Rabindranath, R.; Börner, J.; Hörner, E.; Bentz, A.; Salgado, J.; Han, H.; Böse, H.; Probst, J.; Shamonin, M.; et al. Ultra-Soft PDMS-Based Magnetoactive Elastomers as Dynamic Cell Culture Substrata. PLoS ONE 2013, 8, e76196. [CrossRef]

132. Garcia-Gonzalez, D.; Moreno, M.; Valencia, L.; Arias, A.; Velasco, D. Influence of elastomeric matrix and particle volume fraction on the mechanical response of magneto-active polymers. Compos. Part. B Eng. 2021, 215, 108796. [CrossRef]

133. Tang, J.; Qiao, Y.; Chu, Y.; Tong, Z.; Zhou, Y.; Zhang, W.; Xie, S.; Hu, J.; Wang, T. Magnetic double-network hydrogels for tissue hyperthermia and drug release. J. Mater. Chem. B 2019, 7, 1311-1321. [CrossRef] [PubMed]

134. Li, Y.; Huang, G.; Zhang, X.; Li, B.; Chen, Y.; Lu, T.; Lu, T.J.; Xu, F. Magnetic Hydrogels and Their Potential Biomedical Applications. Adv. Funct. Mater. 2013, 23, 660-672. [CrossRef]

135. Champeau, M.; Heinze, A.H.; Viana, T.N.; de Souza, E.R.; Chinellato, A.C.; Titotto, S. 4D Printing of Hydrogels: A Review. Adv. Funct. Mater. 2020, 30. [CrossRef]

136. Chu, H.; Yang, W.; Sun, L.; Cai, S.; Yang, R.; Liang, W.; Yu, H.; Liu, L. 4D Printing: A Review on Recent Progresses. Micromachines 2020, 11, 796. [CrossRef]

137. Kumar, S.B.; Jeevamalar, J.; Ramu, P.; Suresh, G.; Senthilnathan, K. Evaluation in 4D printing-A review. Mater. Today Proc. 2021, 45, 1433-1437. [CrossRef]

138. Zhang, Y.; Wang, Q.; Yi, S.; Lin, Z.; Wang, C.; Chen, Z.; Jiang, L. 4D Printing of Magnetoactive Soft Materials for On-Demand Magnetic Actuation Transformation. ACS Appl. Mater. Interfaces 2021, 13, 4174-4184. [CrossRef] [PubMed]

139. Hamidi, A.; Tadesse, Y. 3D printing of very soft elastomer and sacrificial carbohydrate glass/elastomer structures for robotic applications. Mater. Des. 2020, 187, 108324. [CrossRef]

140. Lantean, S.; Barrera, G.; Pirri, C.F.; Tiberto, P.; Sangermano, M.; Roppolo, I.; Rizza, G. 3D Printing of Magnetoresponsive Polymeric Materials with Tunable Mechanical and Magnetic Properties by Digital Light Processing. Adv. Mater. Technol. 2019, 4. [CrossRef]

141. Wang, S.; Lee, J.M.; Yeong, W.Y. Smart hydrogels for 3D bioprinting. Int. J. Bioprinting 2015, 1, 3-14. [CrossRef]

142. Sindersberger, D.; Diermeier, A.; Prem, N.; Monkman, G.J. Printing of hybrid magneto active polymers with 6 degrees of freedom. Mater. Today Commun. 2018, 15, 269-274. [CrossRef]

143. Ji, Z.; Yan, C.; Yu, B.; Wang, X.; Zhou, F. Multimaterials 3D Printing for Free Assembly Manufacturing of Magnetic Driving Soft Actuator. Adv. Mater. Interfaces 2017, 4, 1700629. [CrossRef]

144. Tang, J.; Yin, Q.; Shi, M.; Yang, M.; Yang, H.; Sun, B.; Guo, B.; Wang, T. Programmable shape transformation of 3D printed magnetic hydrogel composite for hyperthermia cancer therapy. Extrem. Mech. Lett. 2021, 46, 101305. [CrossRef]

145. Zhu, W.; Li, J.; Leong, Y.J.; Rozen, I.; Qu, X.; Dong, R.; Wu, Z.; Gao, W.; Chung, P.H.; Wang, J.; et al. 3D-Printed Artificial Microfish. Adv. Mater. 2015, 27, 4411-4417. [CrossRef]

146. Saroia, J.; Wang, Y.; Wei, Q.; Zhang, K.; Lu, T.; Zhang, B. A review on biocompatibility nature of hydrogels with 3D printing techniques, tissue engineering application and its future prospective. Bio-Des. Manuf. 2018, 1, 265-279. [CrossRef]

147. Markides, H.; Rotherham, M.; EI Haj, A.J. Biocompatibility and Toxicity of Magnetic Nanoparticles in Regenerative Medicine. J. Nanomater. 2012, 2012. [CrossRef]

148. Mahmoudi, M.; Simchi, A.; Imani, M.; Shokrgozar, M.A.; Milani, A.S.; Häfeli, U.O.; Stroeve, P. A new approach for the in vitro identification of the cytotoxicity of superparamagnetic iron oxide nanoparticles. Colloids Surf. B 2010, 75, 300-309. [CrossRef] [PubMed]

149. Huang, D.; Chuang, T.; Hung, Y.; Lu, F.; Wu, S.; Mou, C.; Yao, M.; Chen, Y. Internalization of mesoporous silica nanoparticles induces transient but not sufficient osteogenic signals in human mesenchymal stem cells. Toxicol. Appl. Pharmacol. 2008, 231, 208-215. [CrossRef]

150. Sun, C.; Lee, J.S.H.; Zhang, M. Magnetic nanoparticles in MR imaging and drug delivery. Adv. Drug Delivery Rev. 2008, 60, 1252-1265. [CrossRef]

151. Chen, L.-T.; Weiss, L. The Role of the Sinus Wall in the Passage of Erythrocytes Through the Spleen. Blood 1973, 41, 529-537. [CrossRef] [PubMed]

152. Arruebo, M.; Fernández-Pacheco, R.; Ricardo Ibarra, M.; Santamaría, J. Magnetic nanoparticles for drug delivery. Nano Today 2007, 2, 22-32. [CrossRef]

153. Garcia-Gonzalez, D.; Hossain, M. Microstructural modelling of hard-magnetic soft materials: Dipole-dipole interactions versus Zeeman effect. Extreme Mech. Lett. 2021, 48, 101382. [CrossRef]

154. Garcia-Gonzalez, D.; Hossain, M. A microstructural-based approach to model magneto-viscoelastic materials at finite strains. Int. J. Solids Struct. 2021, 208-209, 119-132. [CrossRef]

155. Matin, G.Z.; Zand, M.M.; Tehrani, M.S.; Wendland, B.R.; Dargazany, R. A visco-hyperelastic constitutive model of short- and long-term viscous effects on isotropic soft tissues. Proc. Inst. Mech. Eng. Part. C J. Mech. Eng. Sci. 2019, 234, 3-17. [CrossRef]

156. Dorfmann, A.; Ogden, R. A constitutive model for the Mullins effect with permanent set in particle-reinforced rubber. Int. J. Solids Struct. 2004, 41, 1855-1878. [CrossRef]

157. Garcia-Gonzalez, D.; Landis, C.M. Magneto-diffusion-viscohyperelasticity for magneto-active hydrogels: Rate dependences across time scales. J. Mech. Phys. Solids 2020, 139, 103934. [CrossRef]

158. Hong, W.; Zhao, X.; Zhou, J.; Suo, Z. A theory of coupled diffusion and large deformation in polymeric gels. J. Mech. Phys. Solids 2008, 56, 1779-1793. [CrossRef] 
159. Dortdivanlioglu, B.; Linder, C. Diffusion-driven swelling-induced instabilities of hydrogels. J. Mech. Phys. Solids 2019, 125, 38-52. [CrossRef]

160. Pao, Y.-H. Electromagnetic Forces in Deformable Continua. Mech. Today 1978, 4, 209-305. [CrossRef]

161. Eringen, A.C.; Maugin, G.A. Electrodynamics of Continua I; Springer: New York, NY, USA, 1990.

162. Gérard, A.M. Essential Properties of Electromagnetic Solids. In Continuum Mechanics of Electromagnetic Solids; Elsevier Science Ltd: New York, NY, USA, 1988; Volume 33, pp. 1-61.

163. Dorfmann, A. Nonlinear magnetoelastic deformations. Q. J. Mech. Appl. Math. 2004, 57, 599-622. [CrossRef]

164. Bustamante, R. Transversely isotropic nonlinear magneto-active elastomers. Acta Mech. 2009, 210, 183-214. [CrossRef]

165. Saxena, P.; Hossain, M.; Steinmann, P. A theory of finite deformation magneto-viscoelasticity. Int. J. Solids Struct. 2013, 50, 3886-3897. [CrossRef]

166. Nedjar, B. A modelling framework for finite strain magnetoviscoelasticity. Math. Mech. Solids 2020, 25, 288-304. [CrossRef]

167. Garcia-Gonzalez, D. Magneto-visco-hyperelasticity for hard-magnetic soft materials: Theory and numerical applications. Smart Mater. Struct. 2019, 28, 085020. [CrossRef]

168. Danas, K.; Kankanala, S.; Triantafyllidis, N. Experiments and modeling of iron-particle-filled magnetorheological elastomers. J. Mech. Phys. Solids 2012, 60, 120-138. [CrossRef]

169. Carlson, J.D.; Jolly, M.R. MR fluid, foam and elastomer devices. Mechatronics 2000, 10, 555-569. [CrossRef]

170. Ivaneyko, D.; Toshchevikov, V.; Saphiannikova, M.; Heinrich, G. Mechanical properties of magneto-sensitive elastomers: Unification of the continuum-mechanics and microscopic theoretical approaches. Soft Matter 2014, 10, 2213-2225. [CrossRef]

171. Mukherjee, D.; Bodelot, L.; Danas, K. Microstructurally-guided explicit continuum models for isotropic magnetorheological elastomers with iron particles. Int. J. Non-Linear Mech. 2020, 120, 103380. [CrossRef]

172. Mukherjee, D.; Rambausek, M.; Danas, K. An explicit dissipative model for isotropic hard magnetorheological elastomers. J. Mech. Phys. Solids 2021, 151, 104361. [CrossRef]

173. Zabihyan, R.; Mergheim, J.; Pelteret, J.; Brands, B.; Steinmann, P. FE2 simulations of magnetorheological elastomers: Influence of microscopic boundary conditions, microstructures and free space on the macroscopic responses of MREs. Int. J. Solids Struct. 2020, 193-194, 338-356. [CrossRef]

174. Nam, S.; Stowers, R.; Lou, J.; Xia, Y.; Chaudhuri, O. Varying PEG density to control stress relaxation in alginate-PEG hydrogels for 3D cell culture studies. Biomatererials 2019, 200, 15-24. [CrossRef]

175. Yang, J.; Shao, C.; Meng, L. Strain Rate-Dependent Viscoelasticity and Fracture Mechanics of Cellulose Nanofibril Composite Hydrogels. Langmuir 2019, 35, 10542-10550. [CrossRef]

176. Hu, X.; Zhou, J.; Daniel, W.F.M.; Vatankhah-Varnoosfaderani, M.; Dobrynin, A.V.; Sheiko, S.S. Dynamics of Dual Networks: Strain Rate and Temperature Effects in Hydrogels with Reversible H-Bonds. Macromolecules 2017, 50, 652-659. [CrossRef]

177. Wang, C.; Wiener, C.G.; Fukuto, M.; Li, R.; Yager, K.G.; Weiss, R.A.; Vogt, B.D. Strain rate dependent nanostructure of hydrogels with reversible hydrophobic associations during uniaxial extension. Soft Matter 2019, 15, 227-236. [CrossRef]

178. Delavoipière, J.; Tran, Y.; Verneuil, E.; Chateauminois, A. Poroelastic indentation of mechanically confined hydrogel layers. Soft Matter 2016, 12, 8049-8058. [CrossRef]

179. Esteki, M.H.; Alemrajabi, A.A.; Hall, C.M.; Sheridan, G.K.; Azadi, M.; Moeendarbary, E. A new framework for characterization of poroelastic materials using indentation. Acta Biomater. 2020, 102, 138-148. [CrossRef] [PubMed]

180. Zhang, J.; Zhao, X.; Suo, Z.; Jiang, H. A finite element method for transient analysis of concurrent large deformation and mass transport in gels. J. Appl. Phys. 2009, 105, 093522. [CrossRef]

181. Lucantonio, A.; Nardinocchi, P.; Teresi, L. Transient analysis of swelling-induced large deformations in polymer gels. J. Mech. Phys. Solids 2013, 61, 205-218. [CrossRef]

182. Bouklas, N.; Landis, C.M.; Huang, R. A nonlinear, transient finite element method for coupled solvent diffusion and large deformation of hydrogels. J. Mech. Phys. Solids 2015, 79, 21-43. [CrossRef]

183. Bacca, M.; Mcmeeking, R.M. A viscoelastic constitutive law for hydrogels. Meccanica 2017, 52, 3345-3355. [CrossRef]

184. Liu, Q.; Li, H.; Lam, K.Y. Development of a Multiphysics Model to Characterize the Responsive Behavior of Magnetic-Sensitive Hydrogels with Finite Deformation. J. Phys. Chem. B 2017, 121, 5633-5646. [CrossRef] [PubMed]

185. Liu, Q.; Li, H.; Lam, K.Y. Optimization of Deformable Magnetic-Sensitive Hydrogel-Based Targeting System in Suspension Fluid for Site-Specific Drug Delivery. Mol. Pharm. 2018, 15, 4632-4642. [CrossRef] [PubMed]

186. Liu, Q.; Liu, M.; Li, H.; Lam, K. Multiphysics modeling of responsive deformation of dual magnetic-pH-sensitive hydrogel. Int. J. Solids Struct. 2020, 190, 76-92. [CrossRef]

187. Gebhart, P.; Wallmersperger, T. A general framework for the modeling of porous ferrogels at finite strains. J. Mech. Phys. Solids 2019, 122, 69-83. [CrossRef]

188. Ganguly, S.; Margel, S. Review: Remotely controlled magneto-regulation of therapeutics from magnetoelastic gel matrices. Biotechnol. Adv. 2020, 44, 107611. [CrossRef] [PubMed]

189. Adedoyin, A.A.; Ekenseair, A.K. Biomedical applications of magneto-responsive scaffolds. Nano Res. 2018, 11, 5049-5064. [CrossRef]

190. Ze, Q.; Kuang, X.; Wu, S.; Wong, J.; Montgomery, S.M.; Zhang, R.; Kovitz, J.M.; Yang, F.; Qi, H.J.; Zhao, R. Magnetic Shape Memory Polymers with Integrated Multifunctional Shape Manipulation. Adv. Mater. 2019, 32. [CrossRef] [PubMed] 
191. Kim, C.; Kim, H.; Park, H.; Lee, K.Y. Controlling the porous structure of alginate ferrogel for anticancer drug delivery under magnetic stimulation. Carbohydr. Polym. 2019, 223, 115045. [CrossRef]

192. Thévenot, J.; Oliveira, H.; Sandre, O.; Lecommandoux, S. Magnetic responsive polymer composite materials. Chem. Soc. Rev. 2013, 42, 7099-7116. [CrossRef]

193. Fan, D.; Wang, Q.; Zhu, T.; Wang, H.; Liu, B.; Wang, Y.; Liu, Z.; Liu, X.; Fan, D.; Wang, X. Recent Advances of Magnetic Nanomaterials in Bone Tissue Repair. Front. Chem. 2020, 8. [CrossRef] [PubMed]

194. Hu, R.; Zheng, H.; Cao, J.; Davoudi, Z.; Wang, Q. Self-Assembled Hyaluronic Acid Nanoparticles for pH-Sensitive Release of Doxorubicin: Synthesis and In Vitro Characterization. J. Biomed. Nanotechnol. 2017, 13, 1058-1068. [CrossRef] [PubMed]

195. Zhao, X.; Kim, J.; Cezar, C.A.; Huebsch, N.; Lee, K.; Bouhadir, K.; Mooney, D.J. Active scaffolds for on-demand drug and cell delivery. Proc. Natl. Acad. Sci. USA 2010, 108, 67-72. [CrossRef]

196. Al-Attar, T.; Madihally, S.V. Recent advances in the combination delivery of drug for leukemia and other cancers. Expert Opin. Drug Deliv. 2020, 17, 213-223. [CrossRef]

197. Zheng, H.; Yin, L.; Zhang, X.; Zhang, H.; Hu, R.; Yin, Y.; Qiu, T.; Xiong, X.; Wang, Q. Redox Sensitive Shell and Core Crosslinked Hyaluronic Acid Nanocarriers for Tumor-Targeted Drug Delivery. J. Biomed. Nanotechnol. 2016, 12, 1641-1653. [CrossRef]

198. Antman-Passig, M.; Shefi, O. Remote Magnetic Orientation of 3D Collagen Hydrogels for Directed Neuronal Regeneration. Nano Lett. 2016, 16, 2567-2573. [CrossRef]

199. Socoliuc, V.; Peddis, D.; Petrenko, V.I.; Avdeev, M.V.; Susan-Resiga, D.; Szabó, T.; Turcu, R.; Tombácz, E.; Vékás, L. Magnetic Nanoparticle Systems for Nanomedicine-A Materials Science Perspective. Magnetochemistry. 2020, 6, 2. [CrossRef]

200. Hajinasab, A.; Saber-Samandari, S.; Ahmadi, S.; Alamara, K. Preparation and characterization of a biocompatible magnetic scaffold for biomedical engineering. Mater. Chem. Phys. 2018, 204, 378-387. [CrossRef]

201. Wei, C.; Lv, Y. Preparation and Application of Magnetic Responsive Materials in Bone Tissue Engineering. Curr. Stem Cell Res. Ther. 2020, 15, 428-440. [CrossRef]

202. Fuhrer, R.; Hofmann, S.; Hild, N.; Vetsch, J.R.; Herrmann, I.K.; Grass, R.N.; Stark, W.J. Pressureless Mechanical Induction of Stem Cell Differentiation Is Dose and Frequency Dependent. PLoS ONE 2013, 8, e81362. [CrossRef] [PubMed]

203. Meng, J.; Xiao, B.; Zhang, Y.; Liu, J.; Xue, H.; Lei, J.; Kong, H.; Huang, Y.; Jin, Z.; Gu, N.; et al. Super-paramagnetic responsive nanofibrous scaffolds under static magnetic field enhance osteogenesis for bone repair in vivo. Sci. Rep. 2013, 3, 2655. [CrossRef] [PubMed]

204. Guo, C.; Kaufman, L.J. Flow and magnetic field induced collagen alignment. Biomatererials 2007, 28, 1105-1114. [CrossRef] [PubMed]

205. Tampieri, A.; Landi, E.; Valentini, F.; Sandri, M.; D’Alessandro, T.; Dediu, V.; Marcacci, M. A conceptually new type of bio-hybrid scaffold for bone regeneration. Nanotechnology 2010, 22, 015104. [CrossRef] [PubMed]

206. Bock, N.; Riminucci, A.; Dionigi, C.; Russo, A.; Tampieri, A.; Landi, E.; Goranov, V.; Marcacci, M.; Dediu, V. A novel route in bone tissue engineering: Magnetic biomimetic scaffolds. Acta Biomater. 2010, 6, 786-796. [CrossRef]

207. Silva, E.D.; Babo, P.; Costa-Almeida, R.; Domingues, R.; Mendes, B.B.; Paz, E.; Freitas, P.; Rodrigues, M.; Granja, P.; Gomes, M.E. Multifunctional magnetic-responsive hydrogels to engineer tendon-to-bone interface. Nanomed. Nanotechnol. Biol. Med. 2018, 14, 2375-2385. [CrossRef]

208. Karagiorgis, S.; Tsamis, A.; Voutouri, C.; Turcu, R.; Porav, S.A.; Socoliuc, V.; Vekas, L.; Louca, M.; Stylianopoulos, T.; Vavourakis, V.; et al. Engineered magnetoactive collagen hydrogels with tunable and predictable mechanical response. Mater. Sci. Eng. C 2020, 114, 111089. [CrossRef] [PubMed]

209. Fernandes, M.M.; Correia, D.M.; Ribeiro, C.; Castro, N.; Correia, V.M.G.; Lanceros-Mendez, S. Bioinspired Three-Dimensional Magnetoactive Scaffolds for Bone Tissue Engineering. ACS Appl. Mater. Interfaces 2019, 11, 45265-45275. [CrossRef] [PubMed]

210. Henstock, J.R.; Rotherham, M.; Rashidi, H.; Shakesheff, K.; El Haj, A.J. Remotely Activated Mechanotransduction via Magnetic Nanoparticles Promotes Mineralization Synergistically with Bone Morphogenetic Protein 2: Applications for Injectable Cell Therapy. STEM CELLS Transl. Med. 2014, 3, 1363-1374. [CrossRef]

211. Yang, W.; Zhu, P.; Huang, H.; Zheng, Y.; Liu, J.; Feng, L.; Guo, H.; Tang, S.; Guo, R. Functionalization of Novel Theranostic Hydrogels with Kartogenin-Grafted USPIO Nanoparticles to Enhance Cartilage Regeneration. ACS Appl. Mater. Interfaces 2019, 11,34744-34754. [CrossRef]

212. Abaci, H.E.; Guo, Z.; Coffman, A.; Gillette, B.; Lee, W.-H.; Sia, S.K.; Christiano, A.M. Human Skin Constructs with Spatially Controlled Vasculature Using Primary and iPSC-Derived Endothelial Cells. Adv. Heal. Mater. 2016, 5, 1800-1807. [CrossRef] [PubMed]

213. Pankhurst, A.Q.; Thanh, N.T.K.; Jones, S.K.; Dobson, J. Progress in applications of magnetic nanoparticles in biomedicine. J. Phys. D Appl. Phys. 2009, 42, 224001. [CrossRef]

214. Wu, S.; Hu, W.; Ze, Q.; Sitti, M.; Zhao, R. Multifunctional magnetic soft composites: A review. Multifunct. Mater. 2020, 3, 042003. [CrossRef]

215. Jalili, N.A.; Jaiswal, M.K.; Peak, C.W.; Cross, L.M.; Gaharwar, A.K. Injectable nanoengineered stimuli-responsive hydrogels for on-demand and localized therapeutic delivery. Nanoscale 2017, 9, 15379-15389. [CrossRef] [PubMed]

216. Di, J.; Yu, J.; Wang, Q.; Yao, S.; Suo, D.; Ye, Y.; Pless, M.; Zhu, Y.; Jing, Y.; Gu, Z. Ultrasound-triggered noninvasive regulation of blood glucose levels using microgels integrated with insulin nanocapsules. Nano Res. 2017, 10, 1393-1402. [CrossRef] 
217. Turcheniuk, K.; Khanal, M.; Motorina, A.; Subramanian, P.; Barras, A.; Zaitsev, V.; Kuncser, V.; Leca, A.; Martoriati, A.; Cailliau, K.; et al. Insulin loaded iron magnetic nanoparticle-graphene oxide composites: Synthesis, characterization and application for in vivo delivery of insulin. RSC Adv. 2014, 4, 865-875. [CrossRef]

218. Cheng, J.; Teply, B.A.; Jeong, S.Y.; Yim, C.H.; Ho, D.; Sherifi, I.; Jon, S.; Farokhzad, O.C.; Khademhosseini, A.; Langer, R.S. Magnetically Responsive Polymeric Microparticles for Oral Delivery of Protein Drugs. Pharm. Res. 2006, 23, 557-564. [CrossRef]

219. Casolaro, M.; Casolaro, I. Pulsed release of antidepressants from nanocomposite hydrogels. Biol. Eng. Med. 2017, 3, 1-8. [CrossRef]

220. SNazarizadeh, A.; Asri-Rezaie, S. Comparative study of antidiabetic activity and oxidative stress induced by zinc oxide nanoparticles and zinc sulfate in diabetic rats. AAPS PharmSciTech 2016, 17, 834-843. [CrossRef] [PubMed]

221. Dobson, J. Magnetic nanoparticles for gene and drug delivery. Int. J. Nanomed. 2008, 3, 169-180. [CrossRef]

222. Nguyen, D.T.; Nguyen, N.-M.; Vu, D.-M.; Tran, M.-D.; Ta, V.-T. On-Demand Release of Drug from Magnetic Nanoparticle-Loaded Alginate Beads. J. Anal. Methods Chem. 2021, 2021, 1-7. [CrossRef]

223. Giani, G.; Fedi, S.; Barbucci, R. Hybrid Magnetic Hydrogel: A Potential System for Controlled Drug Delivery by Means of Alternating Magnetic Fields. Polymers 2012, 4, 1157-1169. [CrossRef]

224. Lin, F.; Zheng, J.; Guo, W.; Zhu, Z.; Wang, Z.; Dong, B.; Lin, C.; Huang, B.; Lu, B. Smart cellulose-derived magnetic hydrogel with rapid swelling and deswelling properties for remotely controlled drug release. Cellulose 2019, 26, 6861-6877. [CrossRef]

225. Jalili, N.A.; Muscarello, M.; Gaharwar, A.K. Nanoengineered thermoresponsive magnetic hydrogels for biomedical applications. Bioeng. Transl. Med. 2016, 1, 297-305. [CrossRef] [PubMed]

226. Van der Zee, J. Heating the patient: A promising approach? Ann. Oncol. 2002, 13, 1173-1184. [CrossRef]

227. Ang, K.; Venkatraman, S.; Ramanujan, R. Magnetic PNIPA hydrogels for hyperthermia applications in cancer therapy. Mater. Sci. Eng. C 2007, 27, 347-351. [CrossRef]

228. Meenach, S.A.; Hilt, J.Z.; Anderson, K.W. Poly(ethylene glycol)-based magnetic hydrogel nanocomposites for hyperthermia cancer therapy. Acta Biomater. 2010, 6, 1039-1046. [CrossRef]

229. Park, N.; Kim, J. Hydrogel-Based Artificial Muscles: Overview and Recent Progress. Adv. Intell. Syst. 2020, 2. [CrossRef]

230. Kim, S.-E.; Van Tieu, M.; Hwang, S.Y.; Lee, M.-H. Magnetic Particles: Their Applications from Sample Preparations to Biosensing Platforms. Micromachines 2020, 11, 302. [CrossRef] [PubMed]

231. Chen, Y.-T.; Kolhatkar, A.G.; Zenasni, O.; Xu, S.; Lee, T.R. Biosensing Using Magnetic Particle Detection Techniques. Sensors 2017, 17, 2300. [CrossRef]

232. Sun, T.F.T.; Shi, Q.; Huang, Q.; Wang, H.; Xiong, X.; Hu, C. Magnetic alginate microfibers as scaffolding elements for the fabrication of microvascular-like structures. Acta Biomater. 2018, 66, 272-281. [CrossRef]

233. Fass, J.N.; Odde, D.J. Tensile Force-Dependent Neurite Elicitation via Anti- $\beta 1$ Integrin Antibody-Coated Magnetic Beads. Biophys. J. 2003, 85, 623-636. [CrossRef]

234. Kratz, S.R.A.; Eilenberger, C.; Schuller, P.; Bachmann, B.; Spitz, S.; Ertl, P.; Rothbauer, M. Characterization of four functional biocompatible pressure-sensitive adhesives for rapid prototyping of cell-based lab-on-a-chip and organ-on-a-chip systems. Sci. Rep. 2019, 9, 1-12. [CrossRef] [PubMed]

235. Calvo-Correas, T.; Shirole, A.; Crippa, F.; Fink, A.; Weder, C.; Corcuera, M.A.; Eceiza, A. Biocompatible thermo- and magnetoresponsive shape-memory polyurethane bionanocomposites. Mater. Sci. Eng. C 2019, 97, 658-668. [CrossRef]

236. Wang, L.; Wang, Z.; Li, X.; Zhang, Y.; Yin, M.; Li, J.; Song, H.; Shi, J.; Ling, D.; Wang, L.; et al. Deciphering active biocompatibility of iron oxide nanoparticles from their intrinsic antagonism. Nano Res. 2018, 11, 2746-2755. [CrossRef]

237. Janko, C.; Zaloga, J.; Pöttler, M.; Dürr, S.; Eberbeck, D.; Tietze, R.; Lyer, S.; Alexiou, C. Strategies to optimize the biocompatibility of iron oxide nanoparticles-SPIONs safe by design. J. Magn. Magn. Mater. 2017, 431, 281-284. [CrossRef]

238. Singh, N.; Jenkins, G.; Asadi, R.; Doak, S. Potential toxicity of superparamagnetic iron oxide nanoparticles (SPION). Nano Rev. 2010, 1, 1-15. [CrossRef] [PubMed]

239. Gholami, A.; Rasoul-Amini, S.; Ebrahiminezhad, A.; Abootalebi, N.; Niroumand, U.; Ebrahimi, N.; Ghasemi, Y. Magnetic properties and antimicrobial effect of amino and lipoamino acid coated iron oxide nanoparticles. Minerva Biotecnol. 2016, 28, 177-186. 
240. Bao, Y.; Wen, T.; Samia, A.C.S.; Khandhar, A.P.; Krishnan, K.M. Magnetic nanoparticles: Material engineering and emerging applications in lithography and biomedicine. J. Mater. Sci. 2016, 51, 513-553. [CrossRef] [PubMed]

241. Issa, B.; Obaidat, I.M.; Albiss, B.A.; Haik, Y. Magnetic Nanoparticles: Surface Effects and Properties Related to Biomedicine Applications. Int. J. Mol. Sci. 2013, 14, 21266-21305. [CrossRef] [PubMed]

242. Schlachter, E.K.; Widmer, H.R.; Bregy, A.; Lönnfors-Weitzel, T.; Vajtai, I.; Corazza, N.; Bernau, V.J.; Weitzel, T.; Mordasini, P.; Slotboom, J.; et al. Metabolic pathway and distribution of superparamagnetic iron oxide nanoparticles: In vivo study. Int. J. Nanomed. 2011, 6, 1793-1800. [CrossRef] 